\title{
Evaluation of the Near Real-Time Forecasts Using a Global Nonhydrostatic Model during the CINDY2011/DYNAMO
}

\author{
Tomoe NASUNO \\ Japan Agency for Marine-Earth Science and Technology, Yokohama, Japan \\ Kazuyoshi KIKUCHI \\ IPRC, University of Hawaii, Honolulu, Hawaii \\ Masuo NAKANO, Yohei YAMADA, Mikiko IKEDA \\ Japan Agency for Marine-Earth Science and Technology, Yokohama, Japan \\ and \\ Hiroshi TANIGUCHI \\ Kobe City College of Technology, Kobe, Japan
}

(Manuscript received 15 February 2017, in final form 15 July 2017)

\begin{abstract}
By comparison with satellite and field observations, the comprehensive performance and potential utility of near real-time forecasts using Nonhydrostatic Icosahedral Atmospheric Model (NICAM) are demonstrated by exploiting the Cooperative Indian Ocean Experiment on Intraseasonal Variability in the Year 2011 (CINDY2011)/ Dynamics of the Madden-Julian Oscillation (DYNAMO) campaign. A week-long forecast was run each day using a regionally stretched version of NICAM, with the finest mesh size of $14 \mathrm{~km}$ over the tropical Indian Ocean (IO), throughout the intensive observation period (IOP).

The simulated precipitation time series fairly represented the evolution and propagation of the observed Madden-Julian Oscillation (MJO) events, although a $30 \%$ overprediction of precipitation over the IO domain $\left(60-90^{\circ} \mathrm{E}, 10^{\circ} \mathrm{S}-10^{\circ} \mathrm{N}\right)$ was found on average. Frequencies of strong $\left(>40 \mathrm{~mm}\right.$ day $\left.^{-1}\right)$ precipitation were overpredicted, while those of weak precipitation were underpredicted against satellite observations. Compared with the field observations at Gan Island, the biases in precipitation frequency were less obvious, whereas the growth of lower to middle tropospheric dry $\left(\sim 1 \mathrm{~g} \mathrm{~kg}^{-1}\right)$ and warm $(\sim 1 \mathrm{~K})$ biases were found. Despite these mean biases, temporal variations of the moisture and zonal wind profiles including the MJO events were reasonably simulated.

Using the forecast data the moisture and energy budgets during the IOP were investigated. The diagnosis using the 7-day-mean fields captured the observed features of the MJO events. Meanwhile, significant upward transport of moisture by the grid-resolved high-frequency variability was detected throughout the IOP. The relationship between these high-frequency effects and the simulated MJO or mean biases is also discussed.
\end{abstract}

Keywords CINDY2011/DYNAMO; global nonhydrostatic model; forecast; Madden-Julian Oscillation

Corresponding author: Tomoe Nasuno, Japan Agency for

Marine-Earth Science and Technology, 3173-25, Showa-

machi, Kanazawa-ku, Yokohama, 236-0001, Japan

E-mail: nasuno@jamstec.go.jp

J-stage Advance Published Date: 1 August 2017

(C)2017, Meteorological Society of Japan 


\section{Introduction}

The Cooperative Indian Ocean Experiment on Intraseasonal Variability in the Year 2011 (CINDY2011)/ Dynamics of the Madden-Julian Oscillation (DYNA$\mathrm{MO}$ ) project aimed to promote an understanding of the Madden-Julian Oscillation (Madden and Julian 1971, 1972; MJO) and to improve its modeling and forecasts (Yoneyama et al. 2013, hereafter referred to as Y13; Zhang et al. 2013). The MJO initiation, which had been a difficult aspect of MJO forecasting, was the primary target. Intensive observations were conducted over the Indian Ocean (hereafter, IO) during the period from 1 October 2011 to 15 January 2012, and a large amount of high-quality data was collected (Ciesielski et al. 2014a; Deng et al. 2014; Feng et al. 2014; Moum et al. 2014; Y13). The observations captured many important processes that would be key to a complete understanding of the MJO, such as (1) the deep moistening which led to MJO convective initiation (Gottschalck et al. 2013; Johnson and Ciesielski 2013; Johnson et al. 2015; Y13), (2) the evolution of populations of different cloud types in each stage of the MJO (Bellenger et al. 2015; Feng et al. 2014; Powell and Houze 2013; Ruppert and Johnson 2015; Zuluaga and Houze 2013; Xu and Rutledge 2014), and (3) the sub-daily to seasonal upper ocean variations (Gottschalck et al. 2013; Moum et al. 2014; Seiki et al. 2013; Yokoi et al. 2014; Y13).

During the intensive observation period (IOP), numerical weather prediction and analysis data were provided in real-time by multinational operational centers and institutes (Y13). Modeling studies have also been undertaken with operational forecasts (Gottschalck et al. 2013; Fu et al. 2013; Ling et al. 2014; Kerns and Chen 2014a) and global/regional model simulations (Fu et al. 2015; Hannah and Maloney 2014; Miyakawa et al. 2014; Nasuno 2013; Subramanian and Zhang 2014; Chen et al. 2015; Hagos et al. 2014a, b; Seo et al. 2014; Wang et al. 2015). With regard to the moistening process of the MJO, a special focus has been given on multi-scale processes (Chen et al. 2015; Hagos et al. 2014b; Kerns and Chen 2014a). Hagos et al. (2014b) assessed middle-level moistening as a key factor in shallow-to-deep convection transition, and found greater control by large-scale dynamical forcing than convective-scale effects. Kerns and Chen $(2014 a, b)$ highlighted the critical role of synopticscale systems in MJO initiation and propagation through the moisture variation by enhancement of dry air intrusion. The impacts of the diurnal variation on the moistening process have been examined using atmosphere-ocean coupled models (Chen et al. 2015; Seo et al. 2014) and field observations (Ruppert and Johnson 2015). The significant impact of the diurnal sea surface temperature (SST) variation on moisture buildup prior to the active phase of the MJO was demonstrated; Chen et al. (2015) addressed that the diurnal SST variation contributed to the moisture resurgence in the suppressed period of the MJO event through enhancement of moisture transport associated with the atmospheric mixed Rossby-gravity waves, and Seo et al. (2014) reported the impacts of the collocation of the diurnal peaks of SST and latent heat fluxes. Fu et al. (2013, 2015), who evaluated the forecast skill of operational and research models, concluded that the air-sea coupling enabled a better prediction skill of MJO events.

The moisture or moist static energy (MSE) budgets were assessed as a process-oriented diagnosis, in both observational (Johnson et al. 2015; Sobel et al. 2014) and modeling (Hannah and Maloney 2014; Seo et al. 2014; Subramanian and Zhang 2014; Wang et al. 2015) studies. Sobel et al. (2014) confirmed that the MSE budgets during the life cycle of the CINDY2011/ DYNAMO MJOs generally agreed with those reported in previous studies. The MSE source/sink controls the MJO intensity, and the MSE transport controls the MJO propagation, with comparable contributions from horizontal and vertical advection. An emphasis was placed on the significant roles of radiative-convective feedback (e.g., Hu and Randall 1994) for this period (Hannah and Maloney 2014; Johnson et al. 2015). While these findings were based on a dense network of observations and simulations, the observed MJO events also posed questions, such as the causality between the shallow/congestus clouds and the subsequent evolution of the MJO-scale deep moistening (e.g., Bellenger et al. 2015; Hagos et al. 2014b; Powell and Houze 2013; Ruppert and Johnson 2015). Thus, further investigation for this period is still necessary, as well as an exploration of other MJO cases.

The Japan Agency for Marine-Earth Science and Technology (JAMSTEC) operated near real-time forecasts using a global nonhydrostatic model throughout the IOP (Nasuno 2013; Y13). The model has the merit of seamlessly covering the whole globe with horizontal resolutions that can marginally resolve mesoscale convective systems, which is suited to MJO studies (Miyakawa et al. 2014; Oouchi et al. 2012). The forecast data have been made available for research use (http://www.jamstec.go.jp/iorgc/cindy/obs/obs.html). Nasuno (2013) assessed the forecast skill of MJO in the JAMSTEC forecast system in terms of the real- 
time multivariate MJO (RMM) index (Wheeler and Hendon 2004), and demonstrated that week-long forecasts captured the evolution of the MJO signals. Nasuno (2013) also suggested the potential for a higher forecast skill by reducing systematic model errors but left further analysis unaddressed. The purpose of this study is to evaluate the overall performance of the forecasts, including the abilities and limitations of the current system. Special focus is given to the moist processes, which are essential to the largescale tropical mean state and variability, and how they interact with the dynamics at various temporal (e.g., from sub-daily to intraseasonal) and spatial (from local-convection to basin-wide) scales. A merit of using a global nonhydrostatic model is that the effects of local-scale high-frequency variability on the largescale moisture tendency can be explicitly quantified. These have been implicitly diagnosed by the moisture budget analysis using the observational data or reanalysis products (Yanai et al. 1973; Johnson et al. 2015; Sobel et al. 2014). We also aim to understand the source of model errors through a close comparison with observations, which is useful for improving the model performance. Quantitative assessment allows the model data to be used to better understand the convective episodes that occurred during the IOP.

The remainder of this paper is organized as follows. Section 2 documents the numerical model, simulation setups, and the data used to evaluate the model outputs. Section 3 describes the evaluation of precipitation and soundings in comparison with observations and objective analysis, and moisture budget analysis using the simulation data. A discussion and summary are presented in Sections 4 and 5, respectively.

\section{Data and the forecast system}

The forecast system was based on Nonhydrostatic Icosahedral Atmospheric Model (NICAM; Satoh et al. 2008, 2014; Tomita and Satoh 2004). NICAM is designed for global cloud-resolving numerical experiments, and employs nonhydrostatic governing equations on a quasi-uniform (icosahedral) grid system. To save computational time and to achieve real-time forecasts, a regionally stretched version (Tomita 2008a) was used with a horizontal grid size ranging from 14 $\mathrm{km}$ at $8^{\circ} \mathrm{S}, 80^{\circ} \mathrm{E}$ (i.e., the location of research vessel, Mirai) to $56 \mathrm{~km}$ on the opposite side of the globe (Fig. 1a). Forty vertical levels were taken, with the lowest level at $z=80 \mathrm{~m}$ and the model top at $z=38$ $\mathrm{km}$. Moist processes were explicitly calculated using a six category single-moment bulk cloud microphysical scheme (Tomita 2008b). Turbulent and atmospheric

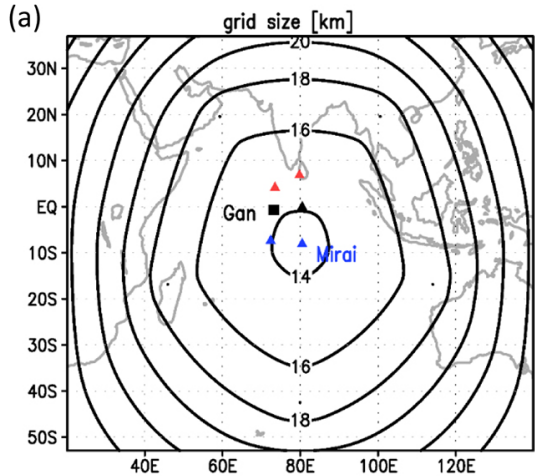

(b)

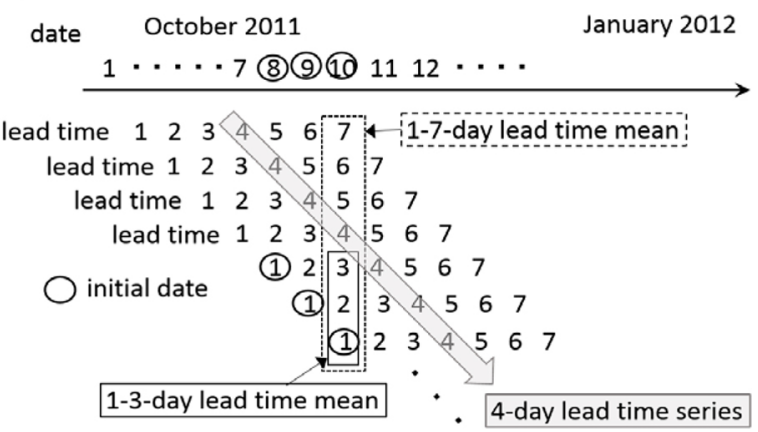

Fig. 1. (a) Grid-size distribution which is used for the near real-time forecasts $(\mathrm{km})$, with focus on the Indian Ocean (modified from Fig. S1 of Nasuno 2013). Triangles indicate the sounding sites (red: northern part of NSA, blue: southern part of SSA), and a square represents Gan Island. (b) A schematic of the forecast time series.

radiation processes were calculated using a modified Mellor-Yamada level 2 scheme (Mellor and Yamada 1982; Noda et al. 2010) and Model Simulation radiation TRaNsfer code (MSTRNX; Sekiguchi and Nakajima 2008), respectively. Sea surface temperature (SST) was predicted using a slab ocean model assuming a uniform mixed layer depth of 50 meter (a typical value in a tropical and subtropical domain; de Boyer Montégut et al. 2004). The initial data for the atmosphere, land surface, and slab ocean models were interpolated from the 1.0-degree gridded National Centers for Environmental Prediction (NCEP) final analysis. A week-long forecast was operated daily as a free run initialized at 0000 UTC throughout the IOP. The SST was nudged to the initial value at a relaxation time of five days in order to avoid a systematic drift.

For the validation of the forecasts, the qualitycontrolled sounding data (Ciesielski et al. 2014a) and 
the Pacific Northwest National Laboratory (PNNL) Combined Retrieval (CombRet) product (Feng et al. 2014) obtained during the CINDY2011/DYNAMO field operation at Gan Island $\left(73.2^{\circ} \mathrm{E}, 0.7^{\circ} \mathrm{S}\right)$ were used. The CombRet product covers the period between 10 October 2011 and 7 February 2012 at 30-second intervals. The liquid water path (LWP) and ice water path (IWP) retrieved from the Ka-band ARM zenith radar (KAZR) and the S-band dual-polarization Doppler radar (S-Pol) data by the PNNL combined remote sensor retrieval algorithm (COMBRET), and the surface precipitation rate from surface meteorological measurements were used in this study. Tropical Rainfall Measuring Mission (TRMM) 3B42v7 (Huffman et al. 2007) was used to evaluate precipitation over the IO domain. The resolution of TRMM 3B42v7 is $0.25^{\circ}$ $\times 0.25^{\circ}$ at 3 -hour intervals. The daily mean $1.0^{\circ} \times 1.0^{\circ}$ averaged values were mainly analyzed. The forecasts were also compared with an objective analysis from the European Center for Medium-range Weather Forecasting (ECMWF) Reanalysis (ERA)-interim (Dee et al. 2011) at a horizontal resolution of $1.0^{\circ} \times 1.0^{\circ}$.

\section{Evaluation of the forecasts}

In this section, convection and dynamical fields in the forecasts are assessed in comparison with observations and the objective analysis. In this study, time series spanning the entire IOP were created from week-long segments of the near real-time forecasts
(Fig. 1b). We mainly present the time series of the average of the 1-3- or 1-7-day lead times. The former reflects a short time response of the convection and circulation to the initial fields, while the latter includes a certain part of intraseasonal variations (Nasuno 2013), although the constraints by the initial conditions are fairly strong throughout the week-long simulations. The "average of the 1-3-day lead time" for 10 October 2011 is defined as the average of the output of the 1-day lead time initialized on 10 October 2011, the output of the 2-day lead time initialized on 9 October 2011, and the output of the 3-day lead time initialized on 8 October 2011 (Fig. 1b). The averaged data on each simulation date were sequentially combined. Similarly, the time series of the 1-7-day lead time average was made from seven runs with the same valid date. The sequential data for the individual lead time (day) was created by combining the outputs of a particular lead time from all the forecasts (Fig. 1b). These datasets allow the assessment of the evolution during the entire IOP and the error growth with respect to the lead time. Without stated, the daily averages calculated from the 3-hourly mean (6-hourly snapshot) outputs for single-layer (multi-layer) variables are presented in this study.

\subsection{Precipitation and water condensates}

Figure 2 shows a time-longitude section of the equatorial surface precipitation in the NICAM fore-

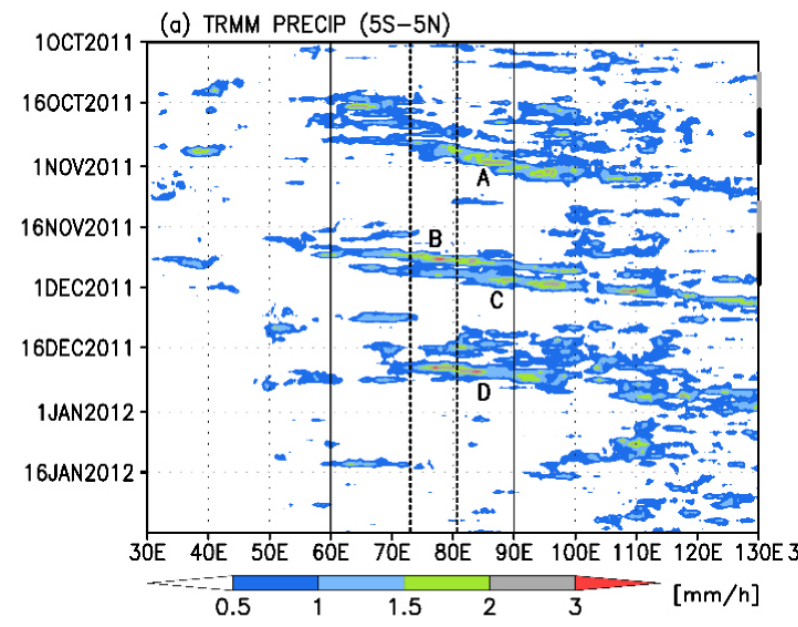

(b) NICAM PRECIP $1-7$ day $(5 \mathrm{~S}-5 \mathrm{~N})$

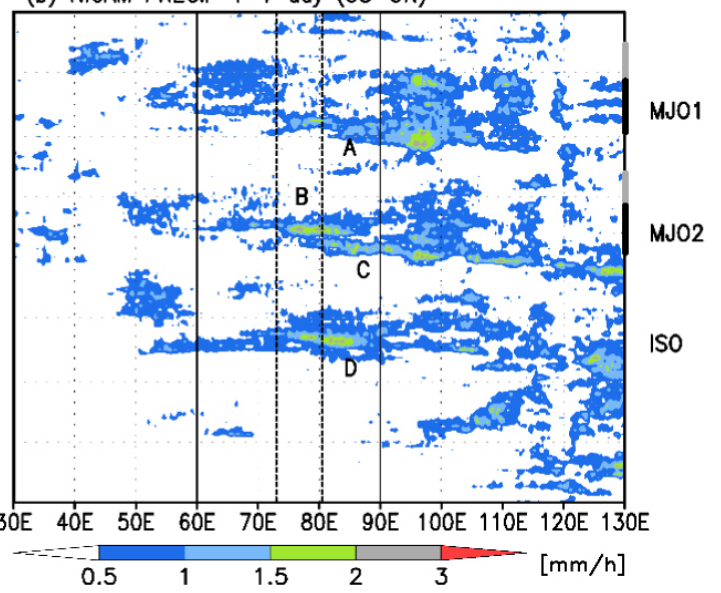

Fig. 2. Time-longitude section of surface precipitation in (a) TRMM 3B42v7 and (b) the NICAM forecasts in $5^{\circ} \mathrm{N}-5^{\circ} \mathrm{S}$. In (b) the time series of the average for the 1-7-day lead time is plotted. The dotted lines are the longitudes of the sounding sites. The $60-90^{\circ} \mathrm{E}$ domain was the major target of this study. The gray and black bars on the right indicate the preconditioning and active periods of the Madden-Julian Oscillation (MJO) events. A, B, C, and D stand for eastward-propagating convective signals. See text for the details. 
casts (the average of the 1-7-day lead time; Fig. 2b) in comparison with TRMM 3B42v7 (Fig. 2a). Three intraseasonal episodes that traveled over the IO reaching the Maritime Continent are clearly visible in both the observation and forecasts. The first and second episodes that occurred in late October and November were identified as MJO events (hereafter referred to as MJO1 and MJO2, respectively) by the RMM Index (Wheeler and Hendon 2004). Based on the intraseasonal (20-80 day period) outgoing longwave radiation (OLR) anomalies over the equatorial IO domain $\left(60-90^{\circ} \mathrm{E}, 10^{\circ} \mathrm{S}-10^{\circ} \mathrm{N}\right)$, Nasuno et al. (2015) defined the onset date (preconditioning period) of MJO1 and $\mathrm{MJO} 2$ as 18 (9-17) October and $18(10-17)$ November, respectively. The simulation also captured the loose convective organization associated with the initiation of the MJO events (middle October, middle November, and early December) over the western IO $\left(50-70^{\circ} \mathrm{E}\right)$. Sharp eastward-propagating signals, with a time scale of a few days over the central IO that appeared in the latter period of the MJO episodes, were marginally simulated (e.g., A, B, C, and D in Figs. 2a, b), although the sharpness was reduced by averaging the seven runs. These results suggest the usefulness of the model outputs for the analysis of convective processes in these MJO events.

One of the interests of using a nonhydrostatic model with explicit moist physics is the diagnosis of water condensates. Figure 3 compares the column integrated water condensates in ERA-interim and NICAM, in the latitude ranges including the northern (Figs. 3a, b) and southern (Figs. 3c, d) sounding array (NSA and SSA, respectively). In the northern hemisphere, condensates were formed with good correspondence to the MJO signals in precipitation (Figs. 2, 3a, b), including those over the western IO during the preconditioning
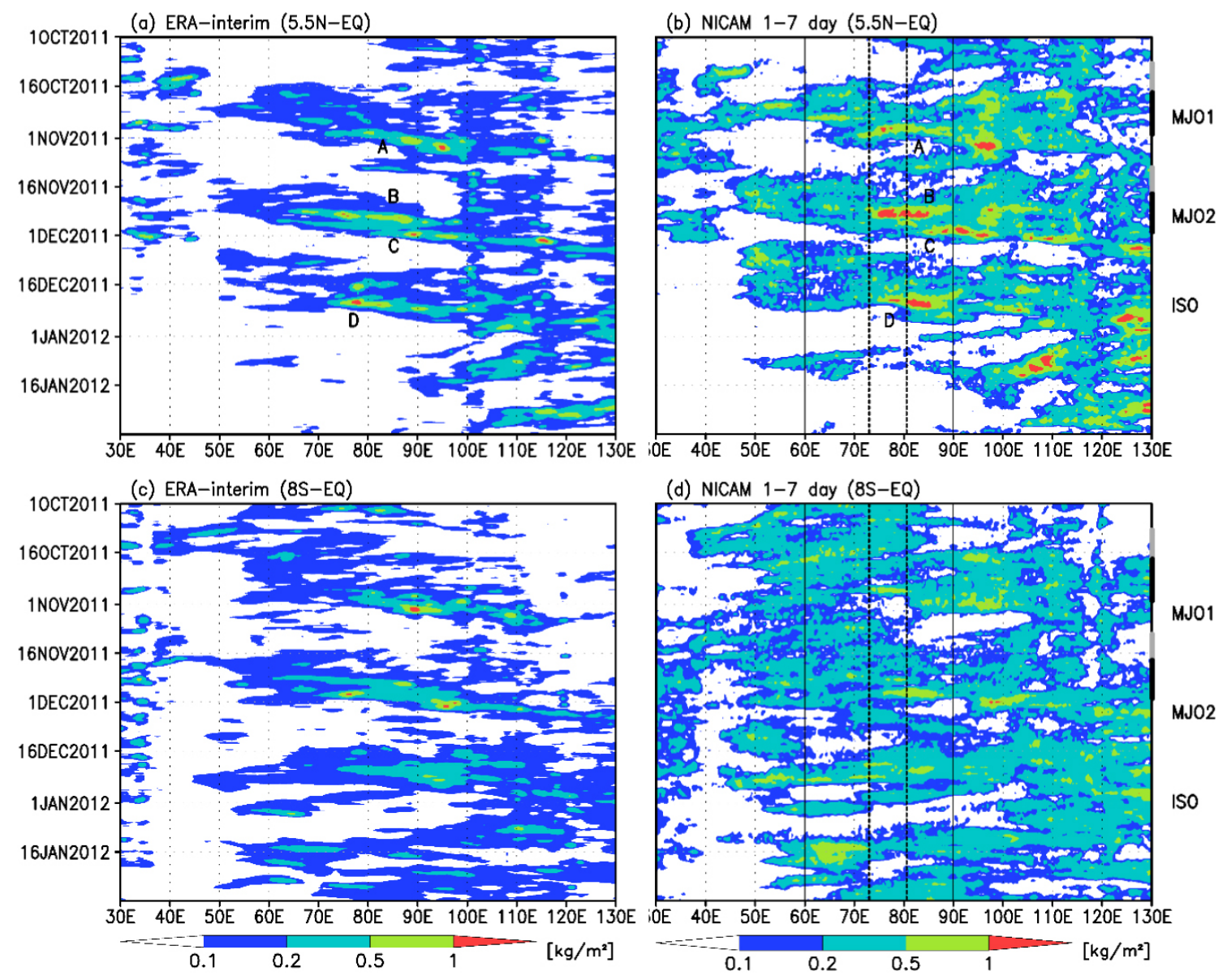

Fig. 3. Same as Fig. 2, but for the column integrated water condensates in (a) (c) ERA-interim and (b) (d) the NICAM simulations, averaged in (a) (b) $0-5.5^{\circ} \mathrm{N}$ and (c) (d) $0-8^{\circ} \mathrm{S}$. 
periods. In the southern hemisphere, condensates were more persistently formed with less obvious intraseasonal variations and eastward propagation. Such a meridional contrast was a prominent feature during the CINDY2011/DYNAMO IOP (Y13; Gottschalck et al. 2013; Johnson and Ciesielski 2013), and can be clearly seen in both datasets. Quantitatively, a greater amount of condensates (approximately double that in ERA-interim) were created in the NICAM forecasts. This is partly attributable to a common bias of NICAM related to cloud microphysics modeling (Roh and Satoh 2014; Satoh et al. 2010; Kodama et al. 2012) and partly to the uncertainty in ERA-interim. Evaluations using the field data are presented later in this section.

Horizontal distributions of the IOP mean daily precipitation in TRMM 3B42v7 and the NICAM forecasts are compared in Fig. 4, together with those of the standard deviation. A peak precipitation zone to the south of the Equator (Fig. 4a) corresponded to the intertropical convergence zone (ITCZ) (Johnson and Ciesielski 2013; Y13). The standard deviation was high along the ITCZ and to the east of NSA (Fig. $4 \mathrm{c})$. These aspects were reasonably simulated in the NICAM forecasts but with an excessive amount of precipitation (Figs. 4b, d). The excessive precipitation in the northeastern IO tended to form a northern hemisphere ITCZ. This tendency is also found in the mean bias (Fig. S1a) and may be related to the easterly bias there (Fig. S1b) through moisture advection from the Maritime Continent.

Frequency distributions of precipitation intensity (1.0-degree gridded daily mean values) in TRMM 3B42v7, the NICAM forecasts, and ERA-interim are compared in Fig. 5a. The frequencies were normalized by the number of precipitating grids $\left(>5 \mathrm{~mm} \mathrm{day}^{-1}\right)$ sampled from the IO domain $\left(60-90^{\circ} \mathrm{E}, 10^{\circ} \mathrm{N}-10^{\circ} \mathrm{S}\right)$ for the IOP (123 days; $123 \times 7$ days for the NICAM forecasts) in each dataset (Table 1). In the NICAM forecasts, the occurrences of moderate precipitation $\left(5-40 \mathrm{~mm} \mathrm{day}{ }^{-1}\right)$ were insufficient, while those of intense precipitation $\left(>40 \mathrm{~mm}^{-1 a y}{ }^{-1}\right)$, as well as the number of precipitation-free grid points, were excessive in comparison with TRMM 3B42v7 (Fig. 5a, Table 1). This indicates that the overprediction of the mean precipitation amount (Figs. 4a, b) was due to the frequent occurrence of strong precipitation episodes. In contrast, ERA-interim (Fig. 5a, blue) had the opposite bias to the NICAM forecasts. This may be due to the different treatment of moist convection with different model resolutions. Figures $5 b-d$ compare the precipitation, LWP, and IWP measured (a) TRMM

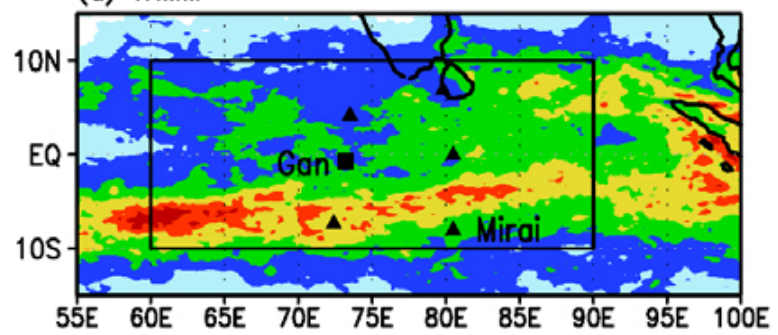

(b) NICAM

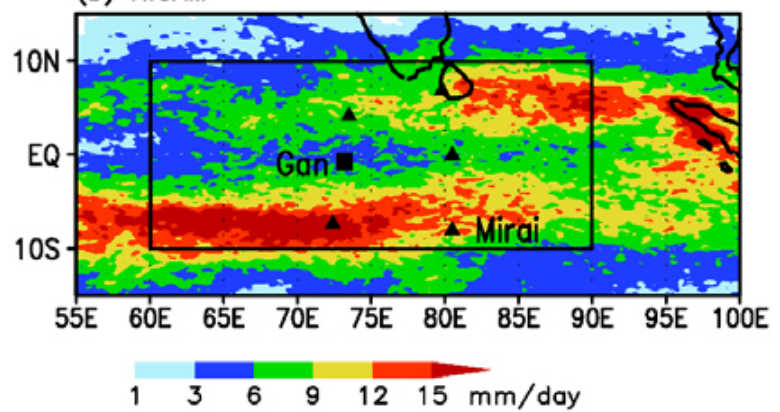

(c) TRMM

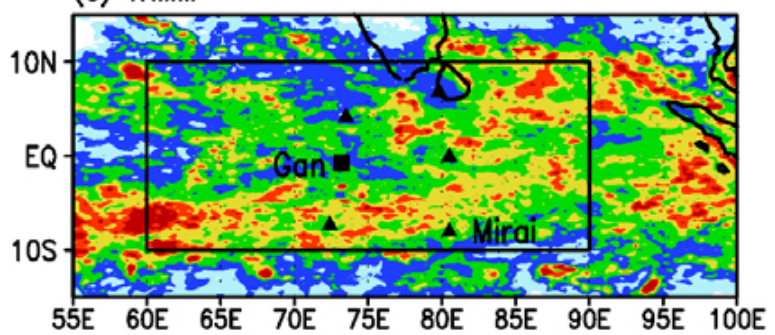

(d) NICAM

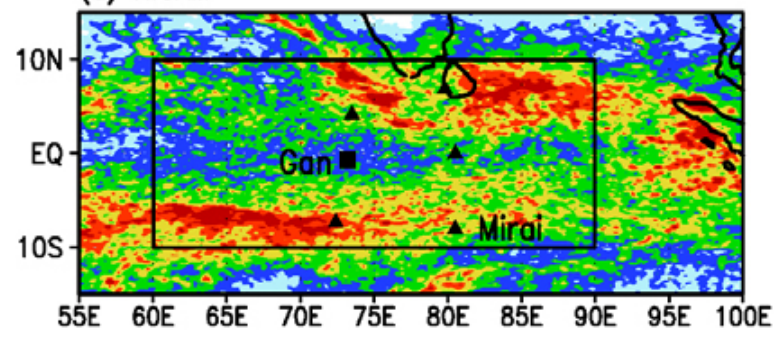

$\begin{array}{lllllll}4 & 8 & 12 & 16 & 20 & 24 & \mathrm{~mm} / \text { day }\end{array}$

Fig. 4. Horizontal distribution of the (a) (b) intensive observation period (IOP) mean precipitation and (c) (d) standard deviation of precipitation in (a) (c) TRMM 3B42v7 and (b) (d) the NICAM simulations. The boxes indicate the analysis domain in Figs. 5, 6, 7, and 10-15. Triangles indicate the sounding sites (square: Gan Island). 
Table 1. Number of 1.0-degree daily precipitating grids ( $>$ $5 \mathrm{~mm} \mathrm{day}^{-1}$ ) in TRMM 3B42v7, NICAM forecasts, and ERA-interim, sampled from the $\left(60-90^{\circ} \mathrm{E}, 10^{\circ} \mathrm{N}-10^{\circ} \mathrm{S}\right)$ domain for 1 October 2011-31 January 2012. The ratio of the precipitating grids to the total number of grids is given in parentheses.

\begin{tabular}{lr}
\hline & number (ratio) \\
\hline TRMM 3B42v7 & $25261(0.315)$ \\
NICAM 1-day & $7175(0.090)$ \\
NICAM 2-day & $14765(0.184)$ \\
NICAM 3-day & $13048(0.162)$ \\
NICAM 4-day & $14493(0.181)$ \\
NICAM 5-day & $13953(0.174)$ \\
NICAM 6-day & $13996(0.175)$ \\
NICAM 7-day & $12368(0.154)$ \\
ERA-interim & $45638(0.570)$ \\
\hline
\end{tabular}

(a) Precipitation Frequency ( $>5 \mathrm{~mm} /$ day)
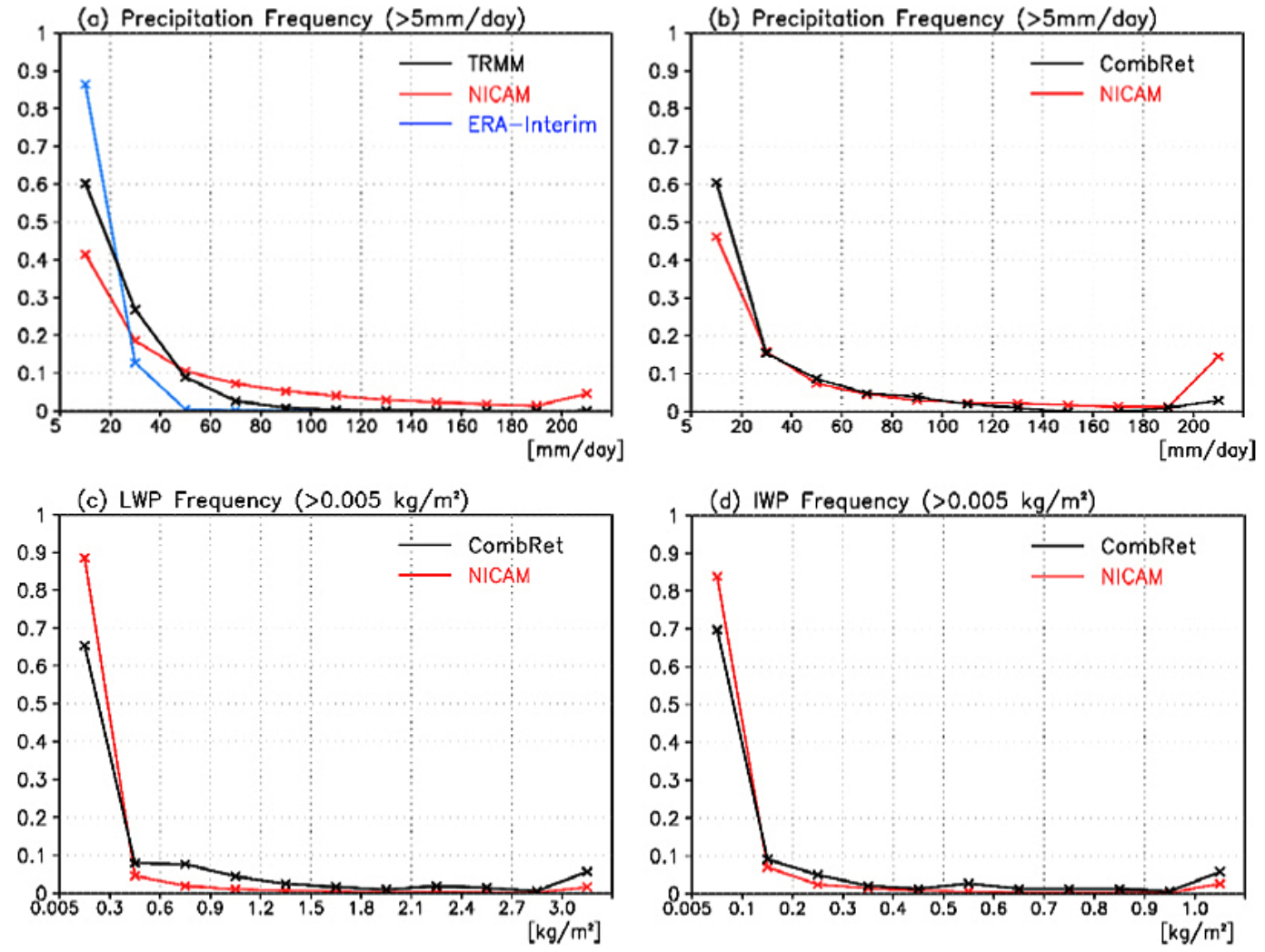

at Gan Island (CombRet) with those in the NICAM forecasts. The CombRet data (30-second intervals) were temporally averaged for comparison with 3-hourly forecast outputs. To reduce the influence of mismatches between local convection in the model and observations, data for the nearest grid point to Gan Island and the surrounding 48 grid points (grid spacing was approximately $14 \mathrm{~km}$ ) in all forecasts were used. Thus, the number of samples in CombRet and the NICAM forecasts were 961 and $961 \times 7$ (days) $\times 49$ (grid points), respectively. For the frequency of water condensates (IWP and LWP), values exceeding $0.005 \mathrm{~kg} \mathrm{~m}^{-2}$ were counted and normalized by the total count of the respective variable in each dataset. The frequency distributions in precipitation agreed well in the range between 20 and $200 \mathrm{~mm}_{\text {day }}{ }^{-1}$ (Fig.

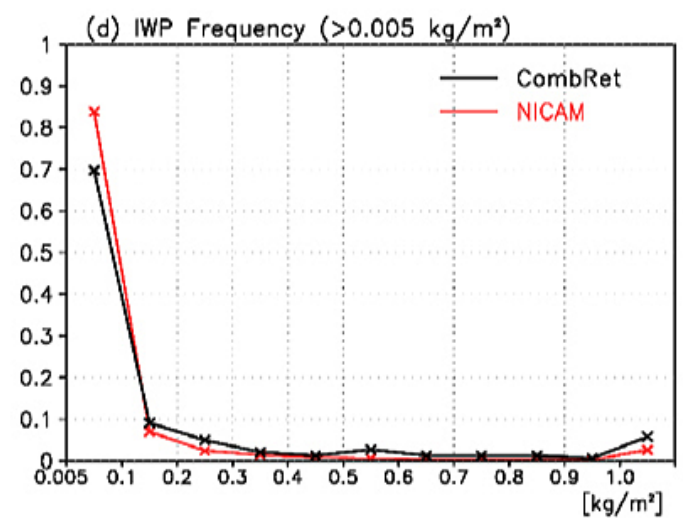

Fig. 5. (a) Frequencies of 1.0-degree gridded daily precipitation for the IOP in TRMM 3B42v7 (black), ERAinterim (blue), and the NICAM forecasts (red), normalized by the number of precipitating grids $\left(>5 \mathrm{~mm}^{-1 a y}{ }^{-1}\right)$ in the $\left(60-90^{\circ} \mathrm{E}, 10^{\circ} \mathrm{S}-10^{\circ} \mathrm{N}\right)$ domain for each case (Table 1). The bin width is $20 \mathrm{~mm}^{-1}{ }^{-1}$. (b) Same as (a), but for the frequencies in CombRet (black) and the NICAM simulations (red lines). Frequencies of the daily mean (c) liquid water path (LWP) and (d) ice water path (IWP) in CombRet (black) and the NICAM forecasts (red), with bin widths of 0.3 and $0.1 \mathrm{~kg} \mathrm{~m}^{-2}$, respectively. The frequencies are normalized by the total occurrences of $>0.005 \mathrm{~kg} \mathrm{~m}^{-2}$ in (c) and (d). The simulation data in (b)-(d) are sampled from seven runs on each simulation date at the nearest grid and the 48 neighboring grids. 
5b). Intense precipitation $\left(>200 \mathrm{~mm} \mathrm{day}^{-1}\right.$ ) occurred approximately three times more frequently in NICAM than in CombRet data. In contrast, lower amounts of water condensates (LWP and IWP) were apparent in the simulations than in the observations (Figs. 5c, d). This implies greater fractions of thin water paths to the total amount in the model. Here, attention should be paid to the fact that Gan Island was located in the minimum zone of mean precipitation along the Equator (Figs. 4a, b). The factors responsible for the larger amount of water condensates in the NICAM forecasts than in ERA-interim over the broad domain (Fig. 3) are discussed in Section 4.

\subsection{Time series over the $S A$ \\ a. Precipitation}

Temporal variation of the precipitation over the NSA, SSA and the IO domain were evaluated in comparison with TRMM $3 \mathrm{~B} 42 \mathrm{v} 7$ and the ERAinterim (Fig. 6). The time series of the average of the earlier (1-3-day) lead time (Figs. 6a, d, g) and all (17-day) lead time (Figs. 6b, e, h) were examined. Generally, the contrast between the active and suppressed period of the MJO events was more clearly simulated in the NICAM forecasts than in ERA-interim (Figs. 6c, f, i). The difference was more notable over the NSA (Figs. 6a-c), where the MJO signals were prominent, than over the SSA, where precipitation was more continuous with high-frequency fluctuations in the ITCZ (Figs. 4a-d, 6d-f). As expected, the 1-3day lead time average outperformed its 1-7-day counterpart in simulating the peak amount of precipitation, especially over the NSA. Both the NICAM forecasts and ERA-interim indicated a relatively good agreement with the TRMM observations for the IO domain (Figs. $6 \mathrm{~g}-\mathrm{i}$ ) but with an overprediction in the preconditioning period of the MJO (marked by the gray bars at the bottom of the panel). Johnson et al. (2015) reported that the budget-derived precipitation based on the radiosonde observations exceeded the TRMM 3B42v7 precipitation during the CINDY2011/ DYNAMO IOP, especially over the SSA, where light and moderate precipitation were more frequent. They argued that the difference between the precipitation estimates was attributable to the insufficient sampling of the shallow precipitation in the TRMM 3B42 product (Xu and Rutledge 2014). This can be also related to the overprediction of precipitation in the NICAM forecasts and ERA-interim during the preconditioning period (Fig. 6). The lower variability of precipitation in ERA-interim than in NICAM may be partly due to the systematic bias of the excessively strong cloud radiative feedback in ERA-interim (Yokoi 2015).

The temporal correlation of the simulated precipitation with TRMM 3B42v7 (cf. Fig. 6), and the area mean precipitation amount are presented in Fig. 7, as a function of lead time. The precipitation amount (Fig. 7a) increased rapidly during the initial two days (i.e., initial shock) and gradually decreased afterward. This behavior was attributable to the lack of an initialization procedure (i.e., data assimilation) to adjust the initial data (from objective analysis; Section 2) to the model balanced state. The precipitation amount exceeded that in TRMM 3B42v7 by $10-30 \%$ after the 1-day lead time. ERA-interim also had a tendency to produce excessive precipitation (by 10-20\%).

The temporal correlation coefficient for the IOP (Fig. 7b) was calculated using the sequential data for each lead time day (Fig. 1b), where the mean bias for each time series (Fig. 7a) was removed. The correlation coefficient retained around $0.8(0.7)$ over the equatorial IO domain $\left(60-90^{\circ} \mathrm{E}, 10^{\circ} \mathrm{S}-10^{\circ} \mathrm{N}\right)$ for the 1-3-day (1-7-day) lead time, although it dropped to around 0.5 over the SSA by the 3-day lead time. A lower score over the SSA than the NSA was also found in ERA-interim, as expected from Fig. 6. These results suggest that the higher predictability over the IO domain and the NSA was due to the presence of pronounced intraseasonal variability, whereas the SSA was characterized by the coexistence of various disturbances with a range of space-time scales (see Figs. $3,4)$, as well as the uncertainty in the satellite product mentioned above.

\section{b. Sounding}

Simulated dynamical and thermodynamical fields were evaluated in comparison with the radiosonde observations at Gan Island. Figure 8 shows the time series of daily-mean zonal wind and water vapor anomalies in the field data and in NICAM on the nearest $1.0^{\circ}$-gridded point. The 1-3- and 1-7-day lead time averages were examined. It is evident that the three intraseasonal events were marked by drastic changes in zonal wind and moisture fields in both the observation and forecasts (Figs. 8a-c). Moistening in the lower to middle troposphere took place during the preconditioning to active periods in the presence of low-level easterly (negative) anomalies, and a stepwise deepening of moisture (e.g., Johnson and Ciesielski 2013, Y13) was evident (e.g., preconditioning periods in Figs. 8d-f). At the peak height of the moisture anomalies, the easterly vertical shear strengthened rapidly due to the intensification of lower-level westerlies (the so-called westerly wind 

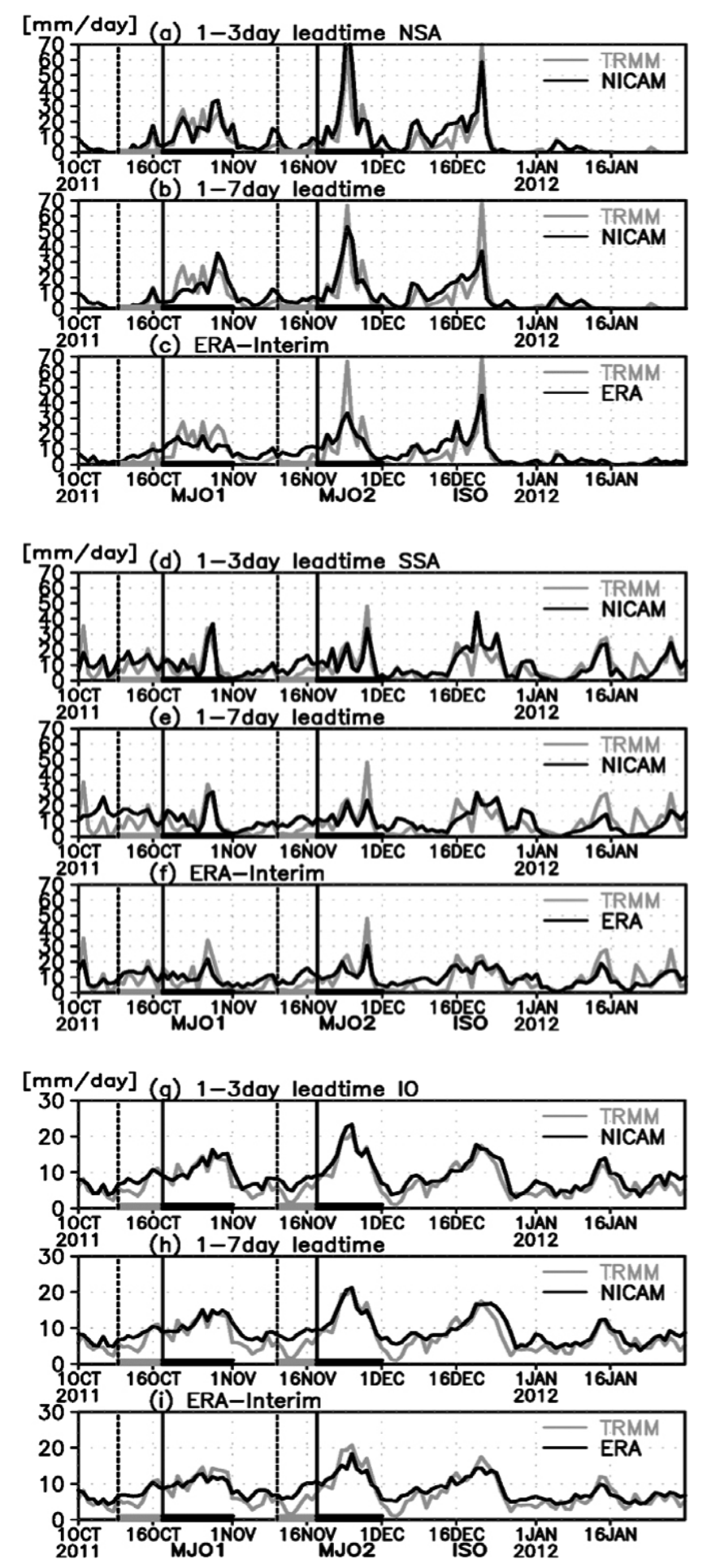

Fig. 6. Time series of daily precipitation averaged in (a)-(c) northern sounding array (NSA: $\left.73-80^{\circ} \mathrm{E}, 0-5.5^{\circ} \mathrm{N}\right)$, (d) $-(\mathrm{f})$ southern sounding array $\left(\mathrm{SSA}: 73-80^{\circ} \mathrm{E}, 0-7.5^{\circ} \mathrm{S}\right)$, and $(\mathrm{g})-(\mathrm{i})$ Indian Ocean domain $\left(60-90^{\circ} \mathrm{E}\right.$, $10^{\circ} \mathrm{S}-10^{\circ} \mathrm{N}$ ) in the NICAM forecasts (black) for (a) (d) (g) 1-3-day and (b) (e) (h) 1-7-day lead time average, and (c) (f) (i) ERA-interim (black) in comparison with TRMM 3B42v7 (gray). The gray and black bars at the bottom indicate the preconditioning and active periods of the MJO events. 
(a) NICAM/TRMM3B42

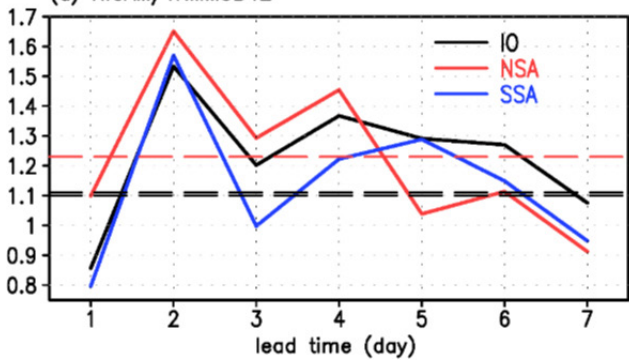

(b) CORR(NICAM,TRMM3B42)

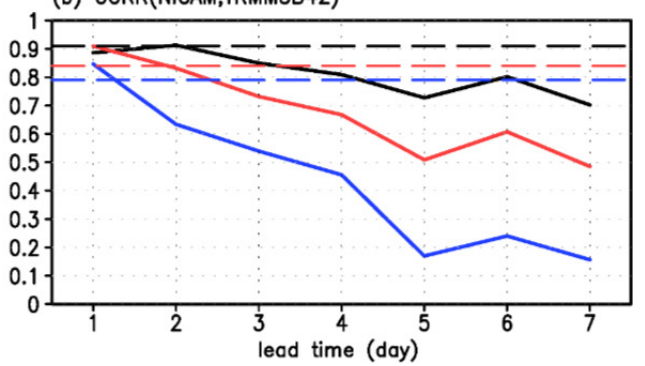

Fig. 7. (a) The area mean precipitation in the NICAM forecasts normalized by that in TRMM 3B42v7 for the IOP and (b) temporal correlation coefficients of precipitation between TRMM 3B42v7 and the NICAM forecasts, as a function of lead time. Averages over the IOP; SSA (blue), NSA (red), equatorial Indian Ocean (60$90^{\circ} \mathrm{E}, 10^{\circ} \mathrm{S}-10^{\circ} \mathrm{N}$ ) regions are drawn. The corresponding values for the ERA-interim are indicated by dashed lines.
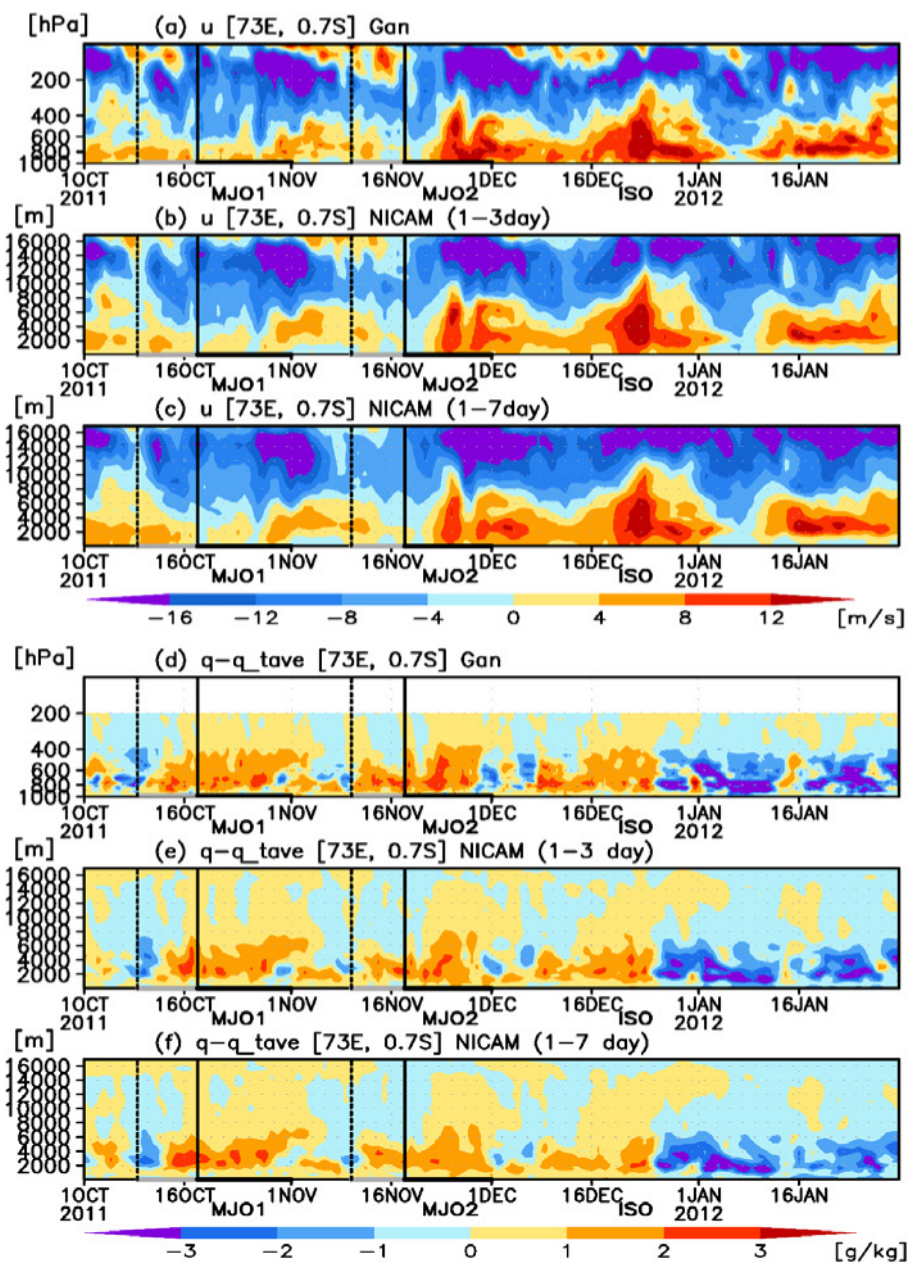

Fig. 8. Time-height section of daily mean (a)-(c) zonal wind and (d)-(f) water vapor anomalies in (a) (d) sounding data at Gan Island $\left(73^{\circ} \mathrm{E}, 0.7^{\circ} \mathrm{S}\right)$ and in the NICAM simulations for (b) (e) 1-3-day and (c) (f) 1-7-day lead time average. The gray and black bars at the bottom indicate the preconditioning and active periods of the MJO events. In (d)-(f) anomalies from the IOP mean value in each time series are plotted. 
burst) in conjunction with upper-level easterlies (e.g., active periods in Figs. 8a-c). These dynamical and thermodynamical signatures of the MJO were consistent with those of past MJO events (e.g., Kikuchi and Takayabu 2004; Kiladis et al. 2005). Embedded in these intraseasonal episodes, moistening events with a short time scale $(<5$ days) were detected several times (e.g., middle October, late October, and late November). Quantitatively, westerlies in the lower troposphere were generally weaker in the forecasts than in the radiosonde data. The results for the 1-7day lead time were overall comparable to those for the 1-3-day lead time, except for some reduction in the short time scale variability (due to a flattening by the ensemble average).

The biases in the IOP mean sounding (forecast minus observation) and root mean square differences are shown in Fig. 9, in a similar manner as those for the ECMWF operational analysis (Ciesielski et al. 2014b) and ERA-interim (Nasuno et al. 2015). As expected from Figs. 8a-c, easterly biases were found below $600 \mathrm{hPa}$ (Fig. 9c). This bias was similar to that in ERA-interim (cf. Fig. 2 of Nasuno et al. 2015) but with approximately twice the magnitude in the NICAM forecasts. Meridional velocity showed no significant mean bias, with root mean square errors in the same magnitude $\left(\sim 2 \mathrm{~m} \mathrm{~s}^{-1}\right)$ as those in zonal velocity (Fig. 9d). Near the surface, cool ( $\sim 1 \mathrm{~K}$ below
$800 \mathrm{hPa})$ and dry biases $\left(0.5 \mathrm{~g} \mathrm{~kg}^{-1}\right.$ below $\left.900 \mathrm{hPa}\right)$ were found (Figs. 9a, b). These were again similar to ERA-interim with approximately twice the magnitude in NICAM forecasts. In the lower to middle troposphere, warm $(\sim 1 \mathrm{~K})$ and dry $\left(1 \mathrm{~g} \mathrm{~kg}^{-1}\right)$ biases developed. The above results indicate that convectively unfavorable conditions generally more prevailed in the forecasts than in the real atmosphere, which may be relevant to the manifestation of very intense local precipitation surrounded by a broad precipitation-free domain (Fig. 5a, Table 1). The biases at Gan Island mentioned above were possibly associated with dynamical responses to the excessive convective activity along the ITCZ to the south of the Equator, such as compensating subsidence, and excitation of a KelvinRossby wave pattern (Fig. S1).

\subsection{Moisture budgets}

The forecast data using a global nonhydrostatic model with explicit representation of moist convection at relatively high resolution allows an estimation of the effects of local-scale high-frequency variability on the mean state and the MJO. In this subsection, moisture budget diagnoses using the forecast outputs are demonstrated. The moisture tendency equation is:

$$
\frac{\partial q}{\partial t}=-\boldsymbol{V} \cdot \nabla q-w \frac{\partial q}{\partial z}-C+E+S_{q}
$$

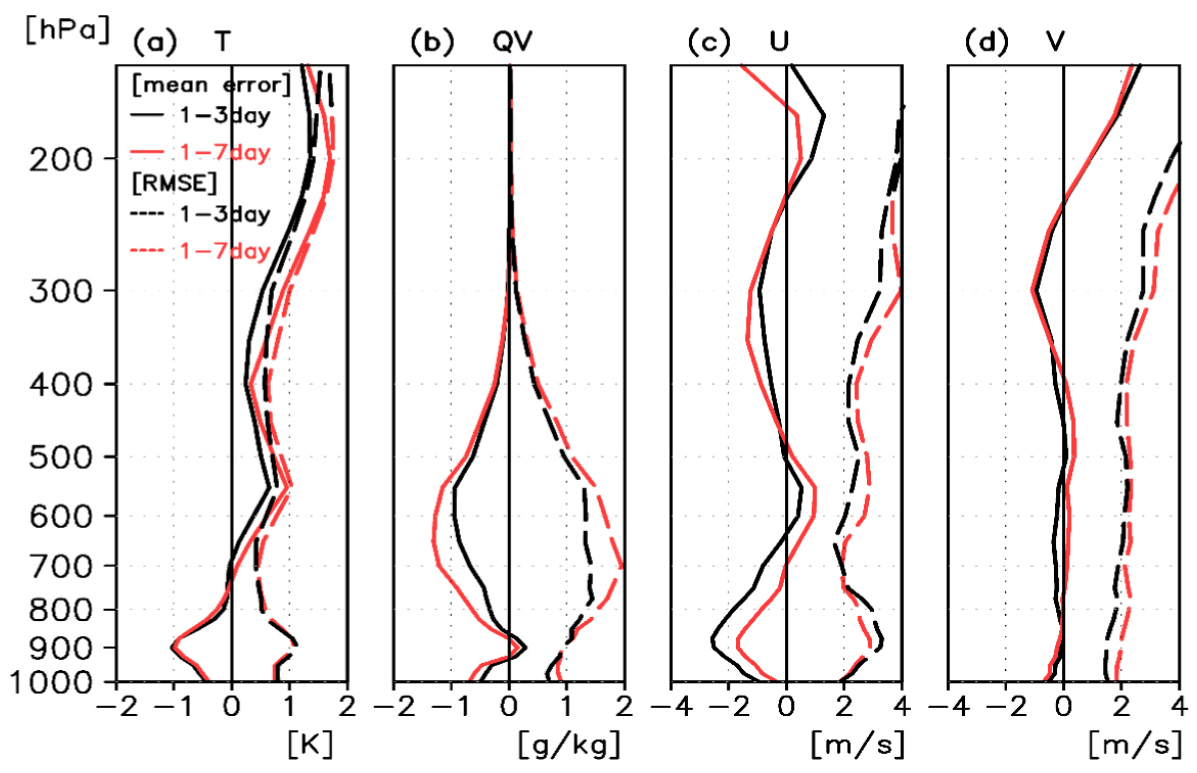

Fig. 9. The IOP mean sounding biases at Gan Island $\left(73^{\circ} \mathrm{E}, 0.7^{\circ} \mathrm{S}\right)$ in (a) temperature, (b) specific humidity, (c) zonal and (d) meridional wind. The NICAM simulations minus observations at 1-3-day (black), and 1-7-day (red) lead time averages (solid lines) and root mean square differences (dashed lines) are plotted. 
where $q, \boldsymbol{V}, w, \nabla$, and $t$ are the water vapor content, horizontal and vertical velocities, horizontal gradient operator, and time, respectively. $C$ and $E$ are the rate of condensation and evaporation of condensates, respectively. $S_{q}$ denotes the sum of other source terms, including turbulent mixing, surface fluxes, and any other numerical effects. To quantify the MJO-related variations and high-frequency effects, the moisture budgets were calculated by separating a variable $X$ into the 7-day-mean value (within each 7-day forecast in NICAM and a moving average in ERA-interim ${ }^{1}$ ) and the deviation from it $\left(X=\bar{X}+X^{\prime}\right)$. The 7-day averaging serves as a low-frequency filter retaining variability with longer than approximately a two-week period (Appendix A). The moisture budgets for the 7-day-mean variables are:

$$
\begin{gathered}
\overbrace{\text { (c) }^{\frac{\partial \bar{q}}{\partial t}}=}^{\underbrace{-\overline{\boldsymbol{V}} \cdot \nabla \bar{q}}_{\text {(b) }}-\bar{w} \frac{\partial \bar{q}}{\partial z}} \underbrace{(\mathrm{f})}_{\text {(a) }} \underbrace{\left(\overline{\boldsymbol{V}^{\prime} \cdot \nabla q^{\prime}}+\overline{w^{\prime} \frac{\partial q^{\prime}}{\partial z}}\right)}_{\text {(d) }} \\
\underbrace{-\bar{C}+\bar{E}+\overline{S_{q}}}_{\text {(e) }},
\end{gathered}
$$

where the overbar indicates a 7-day average. The advection and tendency terms in Eqs. (1) and (2) were computed using the 6-hourly snapshots and the 7-day mean of the 6-hourly snapshots, respectively. In analogy with the budget analysis using the field data
(Johnson et al. 2015; Sobel et al. 2014), precipitation rate was diagnosed from the mass-weighted vertical integral of Eq. (1), and compared with the predicted precipitation rate. Figure 10 shows the mass-weighted vertical integral of $C-E$ (Eq. 1) using $q, \boldsymbol{V}, w$, and daily surface flux (major term of $S_{q}$ ) outputs, the vertical integral of the predicted condensation/evaporation rate (for the NICAM forecasts), and the predicted daily surface precipitation rate. The advection and tendency terms (6-hourly) were averaged for each forecast day (seven runs with different lead time were used for the NICAM forecasts) to meet the other terms. Time series of the budget-derived precipitation well meets that of the predicted precipitation with a much smaller difference in comparison with the biases against TRMM 3B42v7 (Figs. 6h, i). Quantitatively, the root mean square differences between the budgetderived and predicted precipitation for the IOP were $1.3(0.77)$ and $0.72 \mathrm{~mm}$ day $^{-1}$ in the NICAM forecasts (estimates from condensation/evaporation rate) and ERA-interim, respectively. The magnitude of the difference between the budget-derived and predicted precipitation in ERA-interim was comparable to the analysis increment (Yokoi 2015). The larger difference for the NICAM forecasts is attributable to the use of the 6-hourly snapshots, omission of the latent heat of fusion, inaccuracy in the tendency term at the start and end of each simulation, and so on. In the following budget analysis, we focus on the period-mean aspects

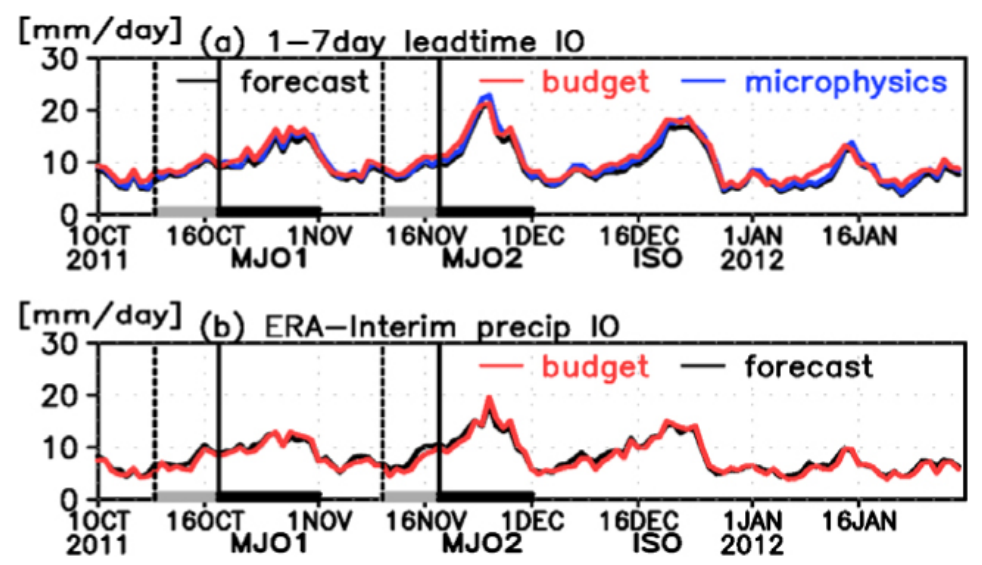

Fig. 10. (a) (b) Same as in Fig. 6 (h) (i), except for the daily precipitation rate which was diagnosed from an apparent moisture sink in Eq. (1) (red), and the predicted precipitation rate (black). The precipitation rate diagnosed from the latent heating rate associated with cloud microphysics (blue) is also plotted in (a). The gray and black bars at the bottom indicate the preconditioning and active periods of the MJO events.

\footnotetext{
${ }^{1}$ The budgets were computed in pressure vertical coordinates for ERA-interim.
} 
and temporal evolution associated with the MJO.

The time-height section of the anomalous (a)-(f) terms of Eq. (2) in NICAM simulations and the period mean profiles averaged over the $\mathrm{IO}$ domain $\left(60-90^{\circ} \mathrm{E}\right.$, $10^{\circ} \mathrm{N}-10^{\circ} \mathrm{S}$ ) are presented in Figs. 11, and 12, respectively (the corresponding time-height sections of vertical velocity and moisture are given in Fig. S2). Temporal variations, with an intraseasonal time scale, are evident in Fig. 11. Deep vertical advective moistening (Fig. 11a), which nearly compensated for the moisture sink (Figs. 11e, f) was pronounced in the active phase of the intraseasonal episodes, in agreement with previous observational findings (Yanai et al. 1973; Johnson and Ciesielski 2013). The active phase was preceded (followed) by moistening (drying) by horizontal advection (Fig. 11b). The moistening due to horizontal advection peaked in the middle troposphere, in good correspondence with the net tendency (Fig. 11c). Similar results were obtained for the CINDY2011/DYNAMO IOP using the field data (Johnson and Ciesielski 2013; Johnson et al. 2015), objective analyses ( $\mathrm{Li}$ et al. 2015; Nasuno et al. 2015; Sobel et al. 2014; Tseng et al. 2015), and simulation data (Hagos et al. 2014b; Hannah and Maloney 2014; Wang et al. 2015). The role of the horizontal advection of the dry air from the subtropics in suppressing convection in the western part of the MJO convection and in pushing the eastward migration of the convective envelope (e.g., Fig. 11b) was argued in previous studies (Maloney and Hartmann 1998; Sugiyama 2009; Maloney 2009; Kim et al. 2014), and in the CINDY2011/DYNAMO publications (Sobel et al. 2014; Kerns and Chen 2014a, b; Yokoi and Sobel 2015). The high-frequency effects (i.e., nonlinear transport of moisture associated with high-frequency variability) were quantified as the difference between the 6-hourly (unfiltered) advection terms and those from the 7-day-mean (low-pass filtered) values, averaged within each 7-day forecast (Fig. 11d). The moistening in the lower to middle troposphere was enhanced in the preconditioning period, whereas the moistening (drying) in the upper (lower) troposphere, indicating the vertical transport of moisture, was pronounced in the mature phase of the intraseasonal episodes. The high-frequency moisture transport is also confirmed in the difference between Figs. 11e and $11 \mathrm{f}$. It is noteworthy that in the preconditioning period, both the 7-day-mean and high-frequency transport enhance moistening in the lower to middle troposphere.

The period-mean profiles of the 6-hourly (snapshot) and 7-day-mean diagnoses in the NICAM simulations were compared with those in ERA-interim (Fig. 12).
The advection terms using the 7-day-mean values show moistening (drying) by vertical (horizontal) advection, which peaked in the lower to middle troposphere for both datasets with comparable magnitudes. In contrast, the 6-hourly diagnoses were very different. In NICAM simulations, top-heavy moistening by vertical advection and middle to lower tropospheric moistening by horizontal advection were apparent, whereas in ERA-interim, the 6-hourly diagnosis was closely similar to the 7-day-mean diagnosis. Such a diverse representation of the high-frequency transport of moisture may be attributable to the differences in the treatment of convection and vertical motion between the models, as well as the horizontal resolution $^{2}$. For example, Fig. 13a shows the mean standard deviation of the 6-hourly temperature and moisture (i.e., magnitude of $T^{\prime}, q^{\prime}$ ) in each forecast (normalized by the IOP mean values), and Fig. 13b shows the same for vertical velocity (i.e., magnitude of $w^{\prime}$ ) together with the IOP mean values, in the NICAM simulations and in ERA-interim. Obviously, the magnitude of the high-frequency variability is more significant in the NICAM forecasts than in ERA-interim. Further discussion is given later in this section.

The thermal and moisture balance was also evaluated in analogy with the apparent heat source, $Q_{1}$ and apparent moisture sink, $Q_{2}$ (Yanai et al. 1973). The budget equations for the dry static energy $s=c_{p} T+g z$ ( $c_{p}$ is the specific heat of dry air at constant pressure, $T$ is temperature, $g$ is acceleration due to gravity, and $z$ is height) for the 6-hourly and the 7-day-mean variables are:

$$
\begin{aligned}
\frac{\partial s}{\partial t}= & -\boldsymbol{V} \cdot \nabla s-w \frac{\partial s}{\partial z}+L(C-E)+S_{s}+Q_{R}, \\
\frac{\partial \bar{s}}{\partial t}= & -\overline{\boldsymbol{V}} \cdot \nabla \bar{s}-\bar{w} \frac{\partial \bar{s}}{\partial z}-\left(\overline{\boldsymbol{V}^{\prime} \cdot \nabla s^{\prime}}+\overline{w^{\prime} \frac{\partial s^{\prime}}{\partial z}}\right) \\
& +L(\bar{C}-\bar{E})+\overline{S_{s}}+\overline{Q_{R}},
\end{aligned}
$$

where $L$ is the latent heat of water, $Q_{R}$ is radiative heating, and $S_{s}$ denotes the sum of other source terms, including turbulent mixing, surface fluxes, and any other numerical effects. In this paper, we refer to the residual terms of Eqs. (1)-(4) as;

\footnotetext{
${ }^{2}$ Data assimilation in ERA-interim may also lead to smoother temporal variation than in the NICAM simulations.
} 
[m] (a) vertical [60-90E, 10S-10N]

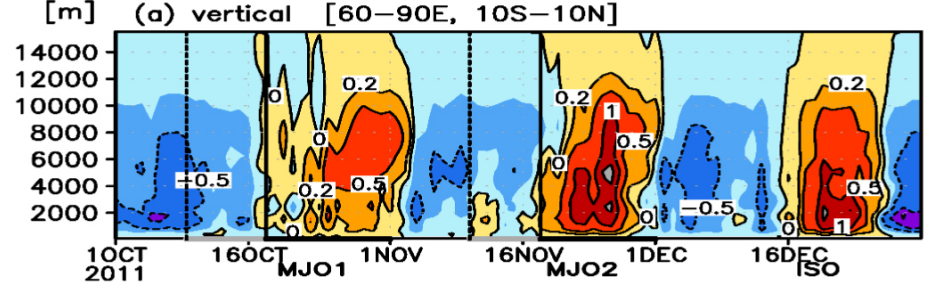

[m] (b) horizontal
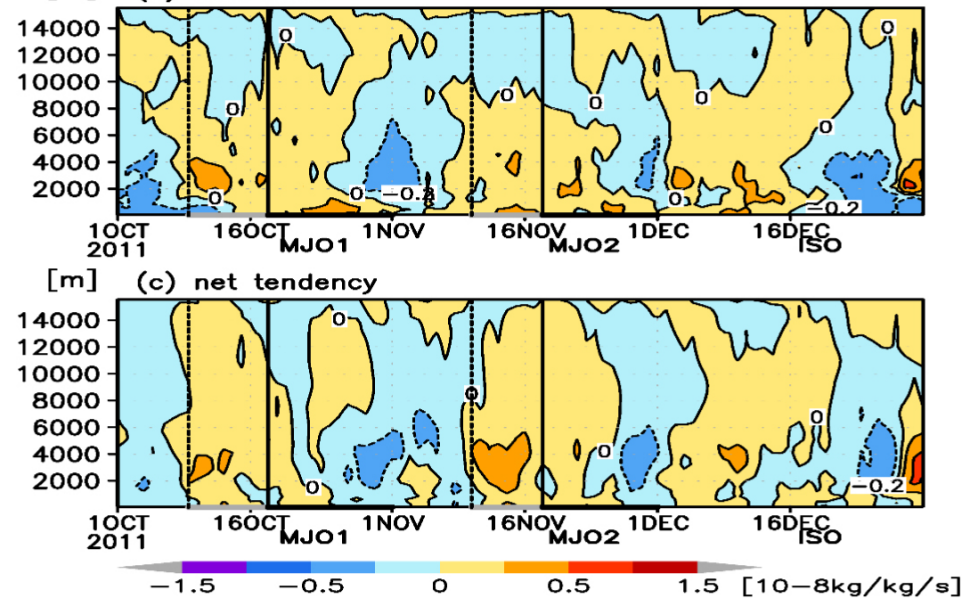

[m] (d) high freqency anom [60-90E, 10S-10N]

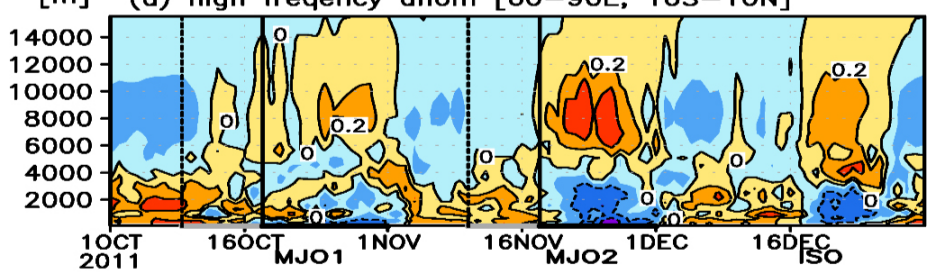

[m] (e) moisture sink anom (cloud microphysics)

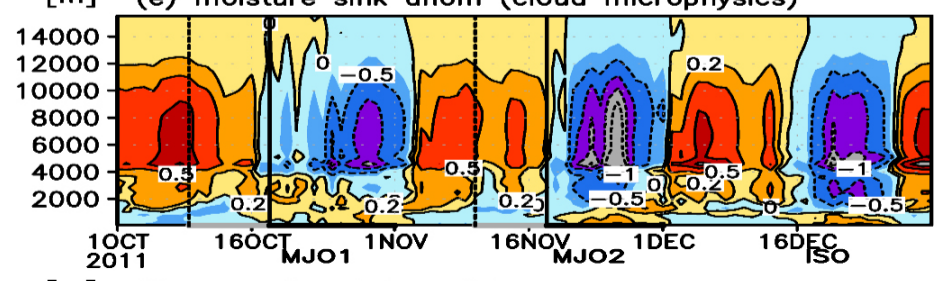

[m] (f) apprent moisture sink anom

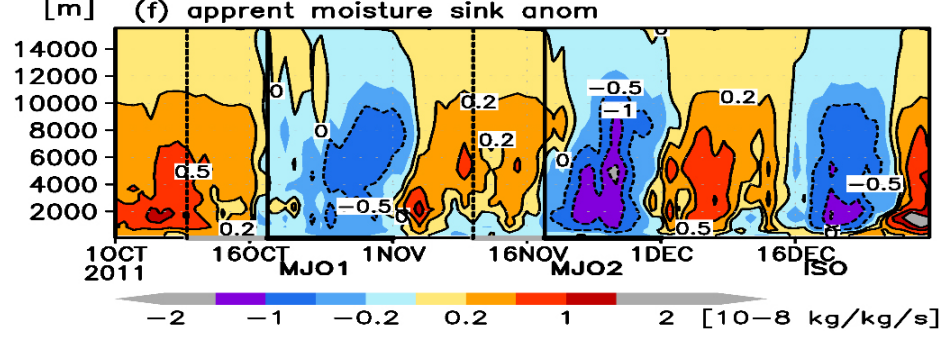

Fig. 11. Time-height section of anomalous (a) vertical advection, (b) horizontal advection, (c) total tendency ( $\partial q / \partial t)$, (d) high-frequency moisture advection, (e) moisture sink associated with cloud microphysics, and (f) apparent moisture sink derived from Eq. (2) in the NICAM simulations averaged in the $\left(60-90^{\circ} \mathrm{E}, 10^{\circ} \mathrm{N}-10^{\circ} \mathrm{S}\right)$ domain. The anomalies from the period mean values are plotted. Each term was calculated using 7-day-mean variables, except for (d). The gray and black bars at the bottom indicate the preconditioning and active periods of the MJO events. 

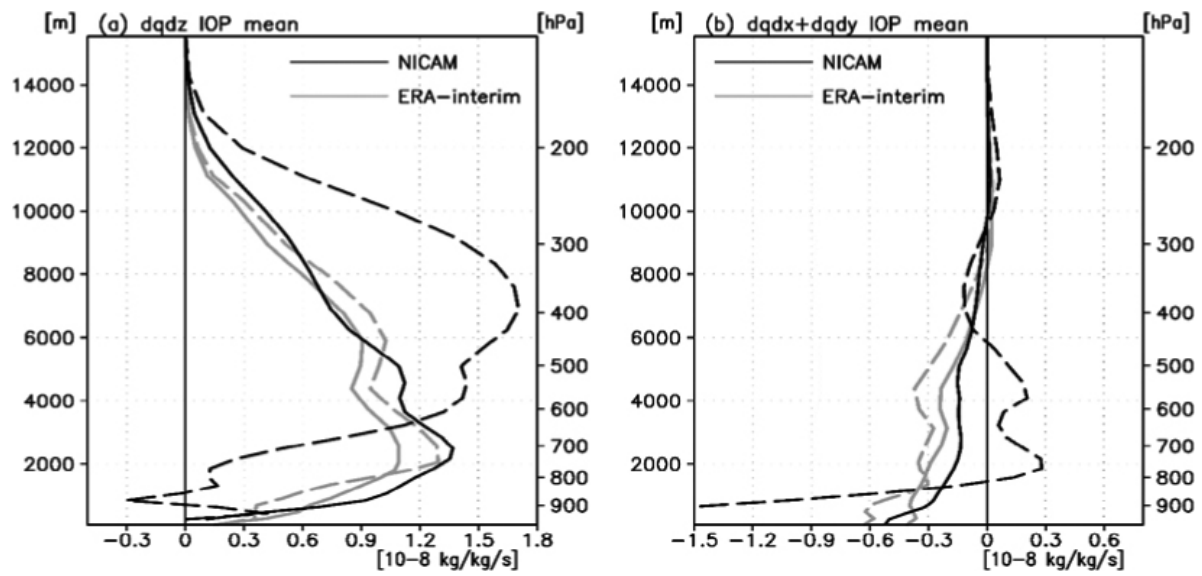

Fig. 12. Vertical profiles of (a) vertical and (b) horizontal advection terms of the moisture tendency equation using the 6-hourly (dashed lines) and 7-day-mean (solid lines) variables in the NICAM simulations (black) and ERA-interim (gray), averaged in the $\left(60-90^{\circ} \mathrm{E}, 10^{\circ} \mathrm{S}-10^{\circ} \mathrm{N}\right)$ domain for the period of October-December 2011.
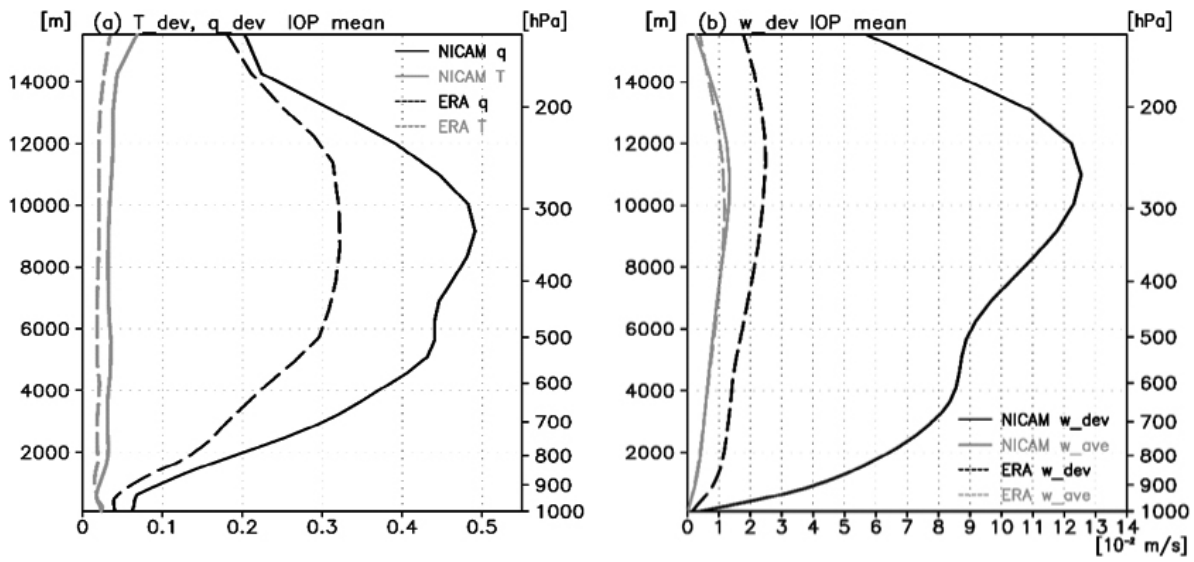

Fig. 13. Vertical profiles of (a) the average of the standard deviations of temperature (gray) and moisture (black) in each forecast, normalized by the IOP mean values, and (b) the average of the standard deviation of vertical velocity in each forecast (black) and the IOP mean values (gray), in the NICAM simulations (solid lines) and ERA-interim (dashed lines) averaged in the $\left(60-90^{\circ} \mathrm{E}, 10^{\circ} \mathrm{S}-10^{\circ} \mathrm{N}\right)$ domain for the period of October-December 2011. In (a), temperature is multiplied by 10 .

$$
\begin{aligned}
Q_{1}(6 \text { hourly }) & \equiv \frac{\partial s}{\partial t}+\boldsymbol{V} \cdot \nabla s+w \frac{\partial s}{\partial z} \\
& =L(C-E)+S_{s}+Q_{R}, \\
Q_{2}(\text { hourly }) & \equiv-L\left(\frac{\partial s}{\partial t}+\boldsymbol{V} \cdot \nabla q+w \frac{\partial q}{\partial z}\right) \\
& =L(C-E)-L S_{q},
\end{aligned}
$$

$$
\begin{aligned}
& Q_{1}(7 \text { day }) \equiv \frac{\partial \bar{s}}{\partial t}+\overline{\boldsymbol{V}} \cdot \nabla \bar{s}+\bar{w} \frac{\partial \bar{s}}{\partial z} \\
& \quad=-\left(\overline{\boldsymbol{V}^{\prime} \cdot \nabla s^{\prime}}+\overline{w^{\prime} \frac{\partial s^{\prime}}{\partial z}}\right)+L(\bar{C}-\bar{E})+\overline{S_{s}}+\overline{Q_{R}} \\
& Q_{2}(7 \text { day }) \equiv-L\left(\frac{\partial \bar{q}}{\partial t}+\boldsymbol{V} \cdot \nabla \bar{q}+\bar{w} \frac{\partial \bar{q}}{\partial z}\right) \\
& \quad=L\left(\overline{\boldsymbol{V}^{\prime} \cdot \nabla q^{\prime}}+\frac{w^{\prime} \frac{\partial q^{\prime}}{\partial z}}{\partial z}\right)+L(\bar{C}-\bar{E})-L \overline{S_{q}}
\end{aligned}
$$


Vertical profiles of Eqs. (5)-(8), averaged in the IO domain for October-December 2011, are presented in Fig. 14. $Q_{1}$ (7day) and $Q_{2}$ (7day) showed similar profiles to the observed $Q_{1}$ and $Q_{2}$ over the SSA (Johnson et al. 2015) ${ }^{3}$, with $Q_{1}$ peaking at the altitudes of 3-10 km (approximately 700-250 hPa) and $Q_{2}$ more weighted in the lower troposphere, both in the NICAM simulations and ERA-interim (Figs. 14a, c). In the observations, the difference between $Q_{1}$ and $Q_{2}$ represents the eddy transport of moist static energy $(h=s+L q)$ plus $Q_{R}$. In the NICAM simulations $Q_{1}$ (6hourly) and $Q_{2}$ (6hourly) were nearly comparable above an altitude of $5 \mathrm{~km}$, indicating that the moist static energy transport was primarily represented by grid-resolved processes ${ }^{4}$. The relatively larger $Q_{2}$ (6hourly) $-Q_{2}$ (7day) compared with $Q_{1}$ (6hourly)$Q_{1}$ (7day) means that the latent heat energy transport accounted for the major part of the high-frequency (eddy) transport. The energy balance mentioned above was essentially led by the vertical advection terms (Figs. 14b, d), suggesting that the weak temperature gradient approximation (Sobel et al. 2001) was well
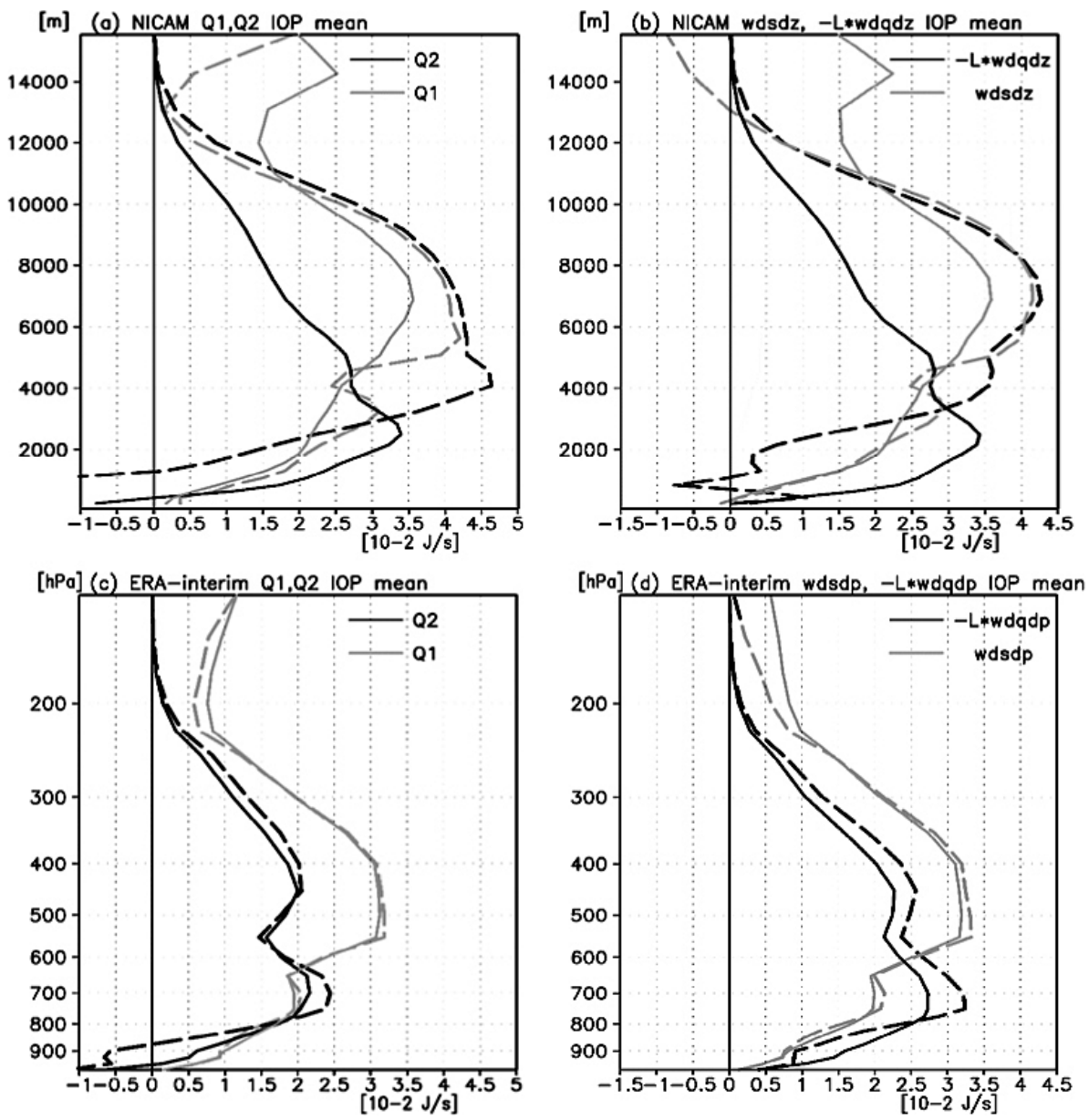

Fig. 14. Vertical profiles of (a) (c) apparent heat source $Q_{1}$ (gray) and apparent moisture sink $Q_{2}$ (black), vertical advection of (b) (d) dry static energy ( $w \partial s / \partial z$; gray) and moisture ( $-L w \partial q / \partial z$; black) for 6-hourly (dashed lines) and 7-day-mean (solid lines) variables in (a) (b) the NICAM simulations and (c) (d) ERA-interim, averaged in the $\left(60-90^{\circ} \mathrm{E}, 10^{\circ} \mathrm{S}-10^{\circ} \mathrm{N}\right)$ domain for the period of October-December 2011.

\footnotetext{
${ }^{3}$ In the observational studies an overbar usually represents spatial average.
}

\footnotetext{
${ }^{4}$ Below the $0{ }^{\circ} \mathrm{C}$ level, subgrid-scale turbulence and its nonlinear interaction with cloud microphysics were pronounced.
} 
established. In contrast to the predominance of gridresolved advection of latent heat energy in the NICAM simulations (Figs. 14a, b), the small differences between the 6-hourly and the 7-day-mean diagnoses in ERA-interim indicate that the subgrid-scale processes (e.g., convection scheme) mostly accounted for the eddy transport of moist static energy [i.e., $Q_{1}$ (7day)$Q_{2}$ (7day)] (Figs. 14c, d).

It is noteworthy that the vertical transport of moisture by the high-frequency variation was much more significant than that of the dry static energy transport even in the NICAM simulations (Fig. 14b). This is owing to the larger magnitude of moisture fluctuation than the temperature fluctuation by approximately two orders (Fig. 13), reflecting the persistence of moisture deviation against the temperature deviation, the latter of which tends to be quickly adjusted through gravity wave emanation.

Chikira (2014) introduced the parameter $\alpha=$ $-L(\partial q / \partial z) /(\partial s / \partial z)$ to assess the physical processes in the MJO simulated in a coupled GCM under weak temperature gradient, paying special attention to its vertical profile. In Chikira's (2014) concept, $\alpha>1$ indicates that vertical moisture advection driven by a thermal forcing (e.g., diabatic heating) is larger than the moisture consumption, leading to destabilization of the atmosphere. Figure 15 shows the time mean profiles of $\alpha$ and their temporal variations in the NICAM simulations and ERA-interim, calculated using the 7-day-mean variables [cf. Chikira (2014) used the low-pass filtered ( $>20$-day period) variables to calculate the $\alpha$ associated with the MJO]. The time mean profiles exhibited destabilization (stabilization) below (above) an altitude of $4 \mathrm{~km}$ in both NICAM and ERA-interim, which agreed with the findings of Chikira (2014) based on the diagnosis of GCM simulations and reanalysis. Interestingly, $\alpha$ in the lower troposphere $(z<3 \mathrm{~km})$ in the model was greater than that in ERA-interim, which is common to the analysis by Chikira (2014), despite the substantial difference in the model framework. A time series of the $\alpha$ profile (normalized by the period mean profile) clearly showed a typical structure associated with the MJO and the intraseasonal events. In general, a higher value of $\alpha$ was located in the lower troposphere during the suppressed periods. It extended into the middle troposphere in the preconditioning periods, and peaked in the upper troposphere during the active periods. The structural change was common in the NICAM simulations and ERA-interim, which was supportive of the arguments made by Chikira (2014). It is likely that the bottom-heavy $\alpha$ profile facilitated the growth of the
MJO through a continuous destabilization in the lower troposphere under weak temperature gradient balance.

\section{Discussion}

The evaluations of precipitation, atmospheric sounding, moisture and dry static energy budgets, and $\alpha$ in Section 3 demonstrated that overall the weeklong NICAM forecasts fairly simulated the evolution of the MJO and intraseasonal events, such as the sharp contrast of precipitation between the active and suppressed period (Fig. 6), gradual deepening of moisture (Figs. 8, 11), and the corresponding variation of the $\alpha$ profile for the 7-day-mean fields (Fig. 15). These were consistent with the evaluations based on the MJO skill score (Nasuno 2013). At the same time, systematic biases were revealed in the mean and statistical properties of precipitation and atmospheric soundings (Figs. 4, 5, 7, 9), as well as distinctive features in the moisture and dry static energy budgets (Figs. 12, 14). In this section, we discuss the linkage among these aspects, which may lead to a better understanding and improvement of the model, and in particular of model physics.

The overprediction of the precipitation amount in the 1.0-degree interpolated daily mean precipitation (Figs. 4-6) in the model is likely due to the excessive occurrence of very intense $\left(>40 \mathrm{~mm}^{\text {day }}{ }^{-1}\right)$ precipitation associated with local vigorous convection with a short time scale $(<12$ hours). The top-heavy profile of the vertical moisture advection (latent heat release) from the 6-hourly outputs that nearly match the adiabatic process (Figs. 12, 14) accounted for the large amount of condensation in the upper troposphere. Convective updrafts tend to induce subsidence (or suppression of upward motion) in the surrounding domain. Figure 16 shows the IOP mean profiles of vertical velocity, temperature, and moisture in the IO domain in the NICAM simulations and ERA-interim. The positive anomaly in the upward motion was evident in the upper troposphere, where the areal coverage of in-cloud upward motion is large (Nasuno and Satoh 2011). The upward motion was slightly weaker in the middle troposphere in the NICAM simulations than in ERA-interim, with a warmer and drier condition in $z=2-10 \mathrm{~km}$. These suggest that in the NICAM forecasts, (1) rapid removal of the uplifted moisture as condensates (Fig. 3) and intense precipitation (Figs. $4,5,7)$ without remaining in the free atmosphere, as well as (2) suppression of upward transport of moisture and reduced adiabatic cooling in a broad domain surrounding the convective updrafts, were responsible for the mean warm and dry biases in the lower to 
middle troposphere (Figs. 9a, b, 16). Considering that high-frequency or subgrid-scale effects are difficult to validate with the existing observational data, the convective behavior in the NICAM simulations should not entirely be erroneous. In fact, the biases in precipitation and water condensates (LWP and IWP) in comparison with the field measurement at Gan Island (Figs. $5 b-d$ ) were not as serious as the biases expected from the comparisons with TRMM 3B42v7 and ERA-interim (Figs. 3, 5a).

The 7-day-mean diagnoses of moisture advection, $Q_{1}$ (7day), $Q_{2}$ (7day), and $\alpha$ in the NICAM simulations (Figs. 12, 14, 15) represented the major aspects of those associated with the MJO reasonably well (e.g., Jonson et al. 2015, 2016; Chikira 2014). In particular, bottom-heavy moistening, which facilitates longlasting moisture accumulation in the lower troposphere to provide favorable conditions for large-scale convective organization (Figs. 11a, 15), was highlighted. In this context, the large amount of upward transport of moisture by grid-resolved convection in a short time scale in the NICAM simulations tended to hinder the growth of the MJO during the developing to mature phases; the anomalous low-level moistening prevailed during these phases in the 7-day-mean diag- nosis (Fig. 11a), whereas the high-frequency upward transport of moisture tended to dry out the lower troposphere (Fig. 11d). Meanwhile, in the suppressed to preconditioning phases of the $\mathrm{MJO}$, the horizontal transport of moisture by the high-frequency variability played an important role in moistening the lower to middle troposphere. The above considerations imply that the relatively weak convective signal associated with the MJO in the NICAM simulations (Nasuno 2013; Kodama et al. 2015; Kikuchi et al. 2017a) can be related to the overdevelopment of the grid-scale convection in the model.

\section{Summary and outlook}

The evolution of convection and dynamical fields simulated in the near real-time forecasts during the CINDY2011/DYNAMO campaign was evaluated in comparison with a satellite product (TRMM 3B42v7), field measurements (soundings, precipitation, water paths), and an objective analysis (ERA-interim). Week-long forecasts were conducted on a daily basis throughout the IOP using a global nonhydrostatic model (NICAM) with explicit moist processes. A regionally stretched grid system centered on $\left(80^{\circ} \mathrm{E}, 8^{\circ} \mathrm{S}\right)$ was employed, with horizontal grid sizes of 14-56
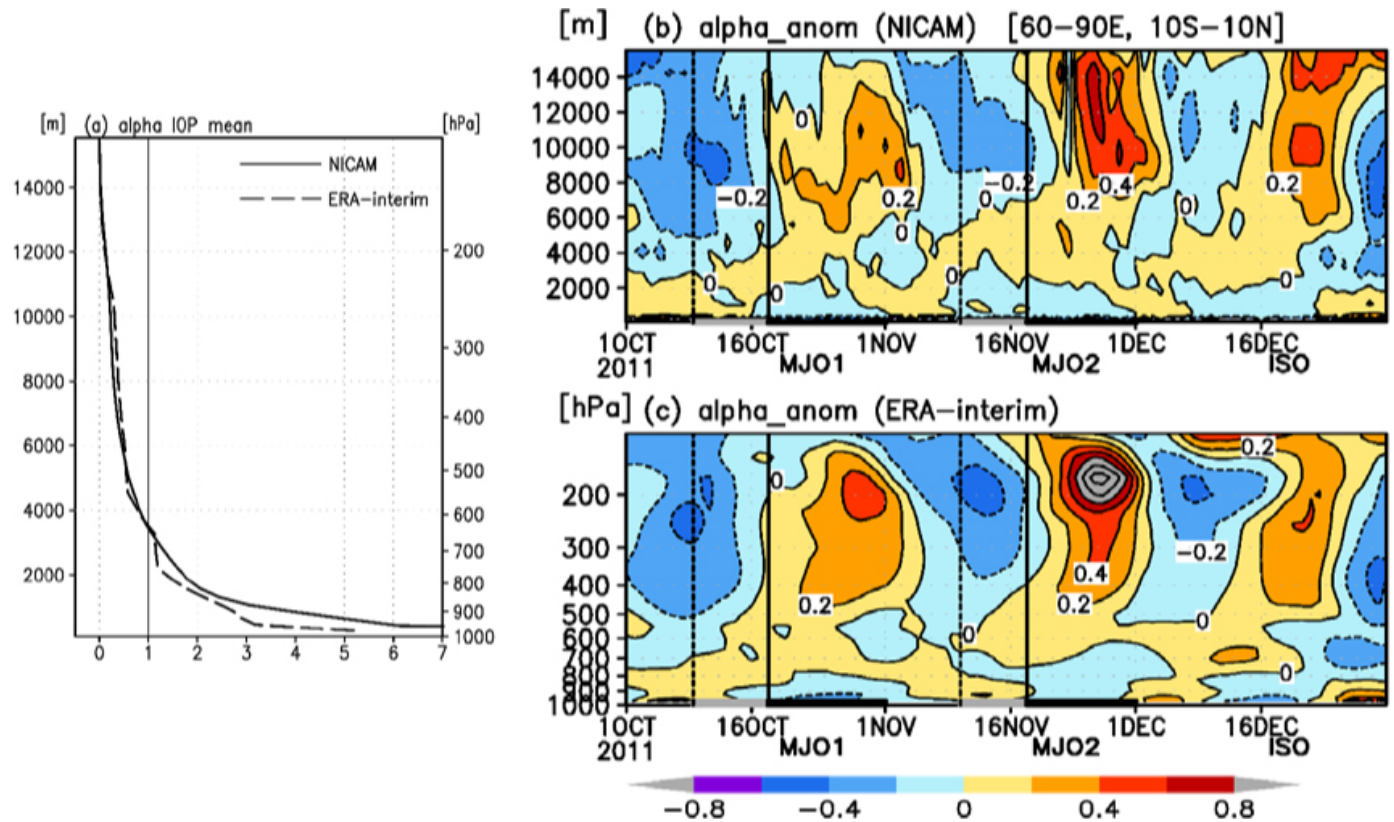

Fig. 15. (a) Vertical profiles of $\alpha=-L(\partial q / \partial z) /(\partial s / \partial z)$ for the 7-day-mean variables in the NICAM simulations (solid lines) and ERA-interim (dashed lines) averaged in the $\left(60-90^{\circ} \mathrm{E}, 10^{\circ} \mathrm{S}-10^{\circ} \mathrm{N}\right)$ domain for the period of October-December 2011. Time-height section of anomalous $\alpha$ from the period mean values in (b) the NICAM simulations and (c) ERA-interim. 

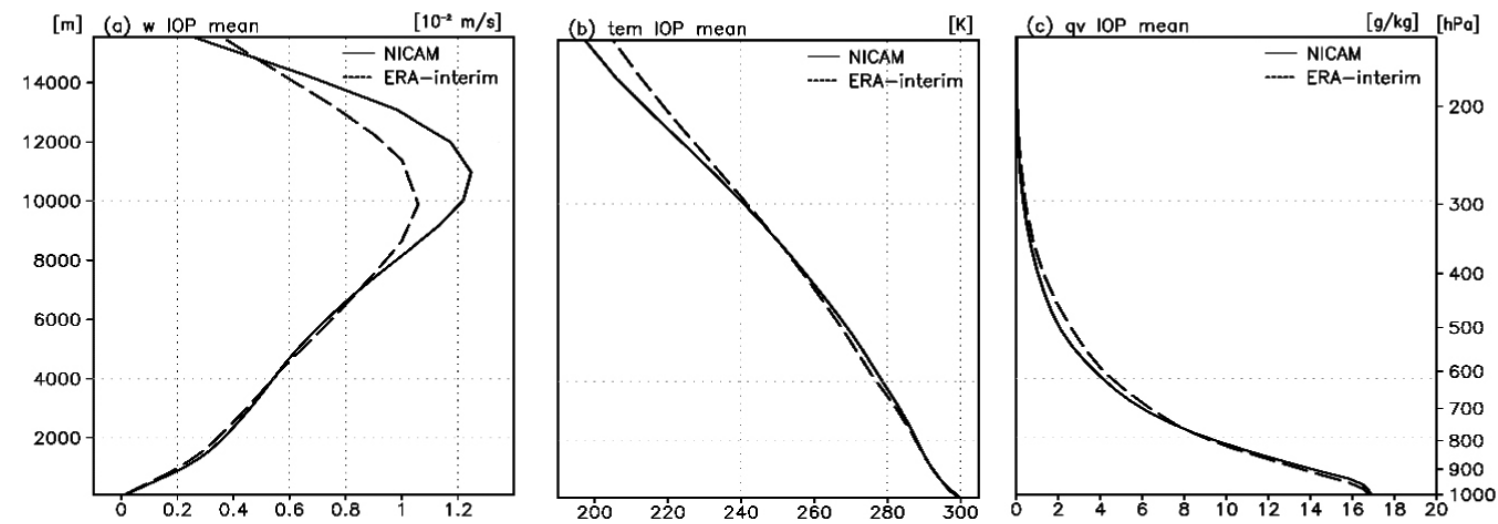

Fig. 16. Vertical profiles of the IOP mean (a) vertical velocity, (b) temperature, and (c) water vapor content in the NICAM forecasts (solid lines) and ERA-interim (dashed lines) averaged in the $\left(60-90^{\circ} \mathrm{E}, 10^{\circ} \mathrm{S}-10^{\circ} \mathrm{N}\right)$ domain.

$\mathrm{km}$ that marginally resolved mesoscale convective systems over the tropical IO.

The daily precipitation time series of the forecasts captured the convective initiation, development, and eastward propagation of the MJO and intraseasonal episodes. The quantitative evaluation of the area-averaged precipitation revealed that the temporal correlation between satellite observation and forecasts was no less than 0.7 for the week-long forecasts over the IO domain $\left(60-90^{\circ} \mathrm{E}, 10^{\circ} \mathrm{N}-10^{\circ} \mathrm{S}\right)$. The correlation was higher over the NSA than the SSA, suggesting a better performance in the presence of a clearer intraseasonal variation. The model showed systematic biases including an initial shock during the first two days because of a rough initialization procedure in the current system. On average, the precipitation amount was overpredicted by $30 \%$ compared to TRMM $3 \mathrm{~B} 42 \mathrm{v} 7$ in the week-long forecasts. Compared with ERAinterim, the contrast between the active and inactive phases of the intraseasonal events was more sharply simulated, which could be attributed to the explicit treatment of convection in NICAM, where precipitation and latent heat release were not allowed until a model grid was fully saturated. This was also relevant to the excessive (modest) occurrences of strong $\left(>40 \mathrm{~mm} \mathrm{day}{ }^{-1}\right)$ precipitation and underprediction (overprediction) of weak precipitation in the NICAM forecasts (ERA-interim) against satellite observations. These suggest that the excessive occurrence of very strong precipitation events was the major source of the overprediction of the total precipitation amount, and it was more prominent in the ITCZ to the south of the Equator than in the convection associated with the MJO. The biases were less obvious in the assessment using the field measurements at Gan Island.

The evaluation of atmospheric sounding data at Gan Island revealed mean model biases of lower tropospheric weak westerlies (maximum $\sim 2.0 \mathrm{~m} \mathrm{~s}^{-1}$ ) and a deficit in temperature $(1 \mathrm{~K})$ and moisture $(0.5$ $\mathrm{g} \mathrm{kg}^{-1}$ ) near the surface. These biases were similar to those found in ERA-interim, but were twice the magnitude in the NICAM forecasts. As the lead time proceeded, dry $\left(\sim 1 \mathrm{~g} \mathrm{~kg}^{-1}\right)$ and warm $(\sim 1 \mathrm{~K})$ biases developed in the free atmosphere, which corresponded to the precipitation biases. Despite these mean errors, temporal evolution of the moisture and zonal wind profiles including the MJO events were reasonably simulated.

The moisture budgets during the IOP were investigated using the forecast time series. Overall, moistening by vertical advection and the residual term (moisture sink) were nearly balanced with each other, and the active phases of the MJO events were preceded (followed) by anomalous moistening (drying) due to horizontal advection, which is consistent with the results obtained using the field data (e.g., Johnson et al. 2015) and an objective analysis (Nasuno et al. 2015).

To quantify the nonlinear effects of the highfrequency variability on the large-scale mean state and the MJO, moisture and dry static energy budget diagnoses were made with the 6-hourly snapshot and 7-day-mean outputs, respectively. In the 6-hourly diagnosis, the latent heat energy advection nearly matched the dry static energy advection, with a topheavy profile. The high-frequency variability induced a substantial upward transport of moisture, which accounted for excessive condensation in the upper tro- 
posphere and the resultant heavy precipitation events, as well as the dry and warm biases in the lower to middle troposphere through suppression of upward motion in the surrounding areas. The high-frequency vertical transport appeared as the grid-resolved processes in the NICAM forecasts, and was more pronounced in the active periods of the MJO events than in the inactive periods. In ERA-interim, a large part of the high-frequency transport was represented by subgrid-scale processes, which led to more moderate time variations.

As a measure of the thermal and moisture balance in the simulated MJO, a parameter $\alpha[-L(\partial q / \partial z) /$ $(\partial s / \partial z)$; Chikira (2014)] was diagnosed. The bottom-heavy profile of $\alpha(>1)$, and its preference for the preconditioning phases of the MJO events were similar among the 7-day-mean diagnosis using the NICAM simulations, that using ERA-interim, and the Chikira's (2014) analysis. In summary, it is likely that the bottom-heavy profile of $\alpha$ (or moistening) associated with the 7-day-mean (low-frequency) fields provided favorable conditions for a large-scale convective organization (e.g., the MJO) through the continuous destabilization in the lower troposphere under weak temperature gradient balance, while the excessive upward transport of moisture by high-frequency variability tended to hinder the growth of the MJO by drying out the lower troposphere. During the preconditioning phases, both the 7-day-mean (low-frequency) and high-frequency horizontal and vertical advections had a tendency to enhance the moistening in the lower to middle troposphere.

One of the possible reasons for the sporadic explosive behavior of convection in the NICAM simulations is the relatively coarse horizontal resolution (for the explicit representation of convection) used in this study. The horizontal resolution affects the representation of in-cloud vertical motion (Miyamoto et al. 2013) and statistics of moist convection (Tomita et al. 2005; Sato et al. 2009; Kajikawa et al. 2016) in the model. The use of finer resolutions, or the implementation of subgrid-scale convective parameterization, is a possible remedy for this problem. Another limitation of the present study is that the week-long forecasts primarily show the convective response to the initial state. To fully investigate the interactions between the convective process and dynamics, free runs with a sufficient integration period are warranted (Miura et al. 2007, 2015; Miyakawa et al. 2014). The high-frequency variability in this study included any disturbances with periods shorter than approximately two weeks, such as convectively coupled equatorial waves (CCEWs), although they were not specified here. The role of CCEWs in the MJO in the statistical sense is still arguable (Kiladis et al. 2009; Dias et al. 2013), but some of the CINDY2011/DYNAMO studies suggested possible roles of CCEWs in the MJO initiation and development (Kubota et al. 2015; Nasuno et al. 2015; Kikuchi et al. 2017b). Further investigations using multiple field data with increased density, together with high-resolution simulation data, are also intended in forthcoming studies.

\section{Supplements}

Figure S1 presents the mean biases of precipitation and lower tropospheric wind field averaged for the IOP in all the week-long NICAM forecasts in comparison with TRMM 3B42v7 and ERA-interim, respectively.

Figure S2 shows the time-height sections of vertical velocity and moisture in the NICAM forecast time series and ERA-interim averaged over the IO domain.

\section{Acknowledgments}

The authors acknowledge two anonymous reviewers for many insightful comments to improve the earlier versions of the manuscript. The first author is indebted to Dr. Kunio Yoneyama for his support in participating in the CINDY2011 project and in handling the sounding data. Dr. Masaki Satoh is acknowledged for his overall support in developing the NICAM forecast system. The authors thank Dr. Satoru Yokoi for the valuable discussions and comments on the physical interpretation of the budget analysis. Dr. Mikiko Fujita is acknowledged for handling the TRMM 3B42v7 data. This work is supported by the JAMSTEC IPRC Initiative, and FLAGSHIP 2020 project of the Ministry of Education, Culture, Sports, Science and Technology (MEXT). The first author is also supported by JSPS KAKENHI Grant Number JP26400475. KK acknowledges the support of NOAA Grant NA13OAR4310165 and the JAMSTEC through its sponsorship of research activities at the IPRC. The Earth Simulator in JAMSTEC was used for the validation of the moisture and energy budget analysis.

\section{Appendix A: \\ Low-pass filtering by a running average}

The amplitude of a sinusoidal signal $\cos (2 \pi t / T)$ with a period $T$ after operating a running average for $T_{\text {ave }}$ is written as $\frac{1}{2 \pi T_{\text {ave }} / T} \sqrt{2\left(1-\cos \left(2 \pi T_{\text {ave }} / T\right)\right)}$ at $t=$ 0 . Figure A1 shows the amplitude of the averaged signal as a function of $T / T_{\text {ave }}$. The running average 


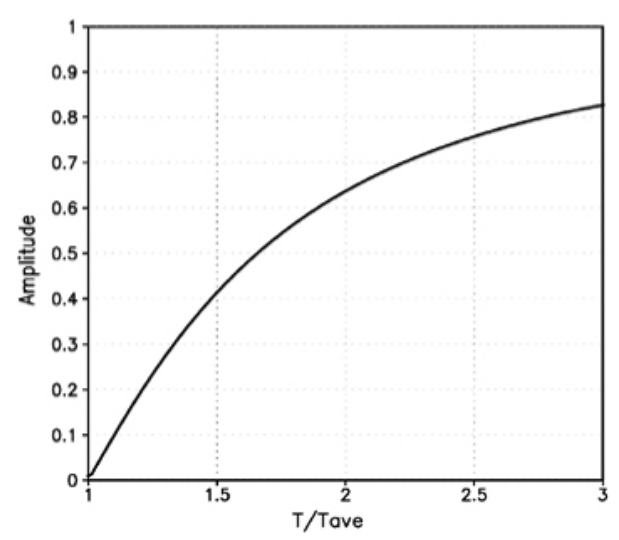

Fig. A1. Amplitude of a signal $\cos (2 \pi t / T)$ at $t=$ 0 after operating a $T_{a v e}$-running average.

serves as a low-pass filter with a period approximately $>16$ days (defined by the amplitude of $1 / \sqrt{2}$, which yields $T / T_{\text {ave }}=2.3$ in Fig. A1).

\section{References}

Bellenger, H., K. Yoneyama, M. Katsumata, T. Nishizawa, K. Yasunaga, and R. Shirooka, 2015: Observation of moisture tendencies related to shallow convection. $J$. Atmos. Sci., 72, 641-659.

Chen, S., M. Flatau, T. G. Jensen, T. Shinoda, J. Schmidt, P. May, J. Cummings, M. Liu, P. E. Ciesielski, C. W. Fairall, R. C. Lien, D. B. Baranowski, N. H. Chi, S. de Szoeke, and J. Edson, 2015: A study of CINDY/ DYNAMO MJO suppressed phase. J. Atmos. Sci., 72, 3755-3779.

Chikira, M., 2014: Eastward-propagating intraseasonal oscillation represented by Chikira-Sugiyama cumulus parameterization. Part II: Understanding moisture variation under weak temperature gradient balance. $J$. Atmos. Sci., 71, 615-639.

Ciesielski, P. E., H. Yu, R. H. Johnson, K. Yoneyama, M. Katsumata, C. N. Long, J. Wang, S. M. Loehrer, K. Young, S. F. Williams, W. Brown, J. Braun, and T. Van Hove, 2014a: Quality-controlled upper-air sounding dataset for DYNAMO/CINDY/AMIE: Development and corrections. J. Atmos. Oceanic Technol., 31, 741-764.

Ciesielski, P. E., R. H. Johnson, K. Yoneyama, and R. K. Taft, 2014b: Mitigation of Sri Lanka Island effects in Colombo sounding data and its impact on DYNAMO analyses. J. Meteor. Soc. Japan, 92, 385-405.

de Boyer Montégut, C., G. Madec, A. S. Fischer, A. Lazar, and D. Iudicone, 2004: Mixed layer depth over the global ocean: An examination of profile data and a profile-based climatology. J. Geophys. Res., 109, C12003, doi:10.1029/2004JC002378.
Dee, D. P., S. M. Uppala, A. J. Simmons, P. Berrisford, P. Poli, S. Kobayashi, U. Andrae, M. A. Balmaseda, G. Balsamo, P. Bauer, P. Bechtold, A. C. M. Beljaars, L. van de Berg, J. Bidlot, N. Bormann, C. Delsol, R. Dragani, M. Fuentes, A. J. Geer, L. Haimberger, S. B. Healy, H. Hersbach, E. V. Hólm, L. Isaksen, P. Kållberg, M. Köhler, M. Matricardi, A. P. McNally, B. M. Monge-Sanz, J.-J. Morcrette, B.-K. Park, C. Peubey, P. de Rosnay, C. Tavolato, J.-N. Thépaut, and F. Vitart, 2011: The ERA-interim reanalysis: Configuration and performance of the data assimilation system. Quart. J. Roy. Meteor. Soc., 137, 553-597.

Deng, M., P. Kollias, Z. Feng, C. Zhang, C. N. Long, H. Kalesse, A. Chandra, V. V. Kumar, and A. Protat, 2014: Stratiform and convective precipitation observed by multiple radars during the DYNAMO/AMIE experiment. J. Appl. Meteor. Climatol., 53, 25032523.

Dias, J., S. Leroux, S. N. Tulich, and G. N. Kiladis, 2013: How systematic is organized tropical convection within the MJO? Geophys. Res. Lett., 40, 1420-1425.

Feng, Z., S. A. McFarlane, C. Schumacher, S. Ellis, J. Comstock, and N. Bharadwaj, 2014: Constructing a merged cloud-precipitation radar dataset for tropical convective clouds during the DYNAMO/AMIE experiment at Addu Atoll. J. Atmos. Oceanic Technol., 31, 1021-1042.

Fu, X., J.-Y. Lee, P.-C. Hsu, H. Taniguchi, B. Wang, W. Wang, and S. Weaver, 2013: Multi-model MJO forecasting during DYNAMO/CINDY period. Climate Dyn., 41, 1067-1081.

Fu, X., W. Wang, J.-Y. Lee, B. Wang, K. Kikuchi, J. Xu, J. $\mathrm{Li}$, and S. Weaver, 2015: Distinctive roles of air-sea coupling on different MJO events: A new perspective revealed from the DYNAMO/CINDY field campaign. Mon. Wea. Rev., 143, 794-812.

Gottschalck, J., P. E. Roundy, C. J. Schreck III, A. Vintzileos, and C. Zhang, 2013: Large-scale atmospheric and oceanic conditions during the 2011-12 DYNAMO field campaign. Mon. Wea. Rev., 141, 4173-4196.

Hagos, S., Z. Feng, C. D. Burleyson, K.-S. S. Lim, C. N. Long, D. Wu, and G. Thompson, 2014a: Evaluation of convection-permitting model simulations of cloud populations associated with the Madden-Julian Oscillation using data collected during the AMIE/ DYNAMO. J. Geophys. Res., 119, 12052-12068.

Hagos, S., Z. Feng, K. Landu, and C. N. Long, 2014b: Advection, moistening, and shallow-to-deep convection transitions during the initiation and propagation of Madden-Julian Oscillation. J. Adv. Model. Earth Syst., 6, 938-949.

Hannah, W. M., and E. D. Maloney, 2014: The moist static energy budget in NCAR CAM5 hindcasts during DYNAMO. J. Adv. Model. Earth Syst., 6, 420-440.

$\mathrm{Hu}$, Q., and D. A. Randall, 1994: Low-frequency oscillations in radiative-convective systems. J. Atmos. Sci., 
51, 1089-1099.

Huffman, G. J., R. F. Adler, D. T. Bolvin, G. Gu, E. J. Nelkin, K. P. Bowman, Y. Hong, E. F. Stocker, and D. B. Wolff, 2007: The TRMM Multisatellite Precipitation Analysis (TMPA): Quasi-global, multi-year, combined-sensor precipitation estimates at fine scale. J. Hydrometeor, , 8, 38-55.

Johnson, R. H., and P. E. Ciesielski, 2013: Structure and properties of Madden-Julian oscillations deduced from DYNAMO sounding arrays. J. Atmos. Sci., 70, 31573179.

Johnson, R. H., P. E. Ciesielski, J. H. Ruppert, Jr., and M. Katsumata, 2015: Sounding-based thermodynamic budgets for DYNAMO. J. Atmos. Sci., 72, 598-622.

Johnson, R. H., P. E. Ciesielski, and T. M. Rickenbach, 2016: A Further look at $Q_{1}$ and $Q_{2}$ from TOGA COARE. Multiscale Convection-Coupled Systems in the Tropics: A Tribute to Dr. Michio Yanai. Meteor. Monogr., 56, Amer. Meteor. Soc., 1.1-1.12.

Kajikawa, Y., Y. Miyamoto, R. Yoshida, T. Yamaura, H. Yashiro, and H. Tomita, 2016: Resolution dependence of deep convections in a global simulation from over 10-kilometer to sub-kilometer grid spacing. Prog. Earth Planet. Sci., 3, 16, doi:10.1186/s40645-0160094-5.

Kerns, B. W., and S. S. Chen, 2014a: ECMWF and GFS model forecast verification during DYNAMO: Multiscale variability in MJO initiation over the equatorial Indian Ocean. J. Geophys. Res., 119, 3736-3755.

Kerns, B. W., and S. S. Chen, 2014b: Equatorial dry air intrusion and related synoptic variability in MJO initiation during DYNAMO. Mon. Wea. Rev., 142, 1326-1343.

Kikuchi, K., and Y. N. Takayabu, 2004: The development of organized convection associated with the MJO during TOGA COARE IOP: Trimodal characteristics. Geophys. Res. Lett., 31, L10101, doi:10.1029/2004GL 019601.

Kikuchi, K., C. Kodama, T. Nasuno, M. Nakano, H. Miura, M. Satoh, A. T. Noda, and Y. Yamada, 2017a: Tropical intraseasonal oscillation in an AMIP-type experiment by NICAM. Climate Dyn., 48, 2507-2528.

Kikuchi, K., G. N. Kiladis, J. Dias, and T. Nasuno, 2017b: Convectively coupled equatorial waves within the MJO during CINDY/DYNAMO: Slow Kelvin waves as building blocks. Climate Dyn., doi:10.1007/s00382017-3869-5.

Kiladis, G. N., K. H. Straub, and P. T. Haertel, 2005: Zonal and vertical structure of the Madden-Julian oscillation. J. Atmos. Sci., 62, 2790-2809.

Kiladis, G. N., M. C. Wheeler, P. T. Haertel, K. H. Straub, and P. E. Roundy, 2009: Convectively coupled equatorial waves. Rev. Geophys., 47, RG2003, doi:10.1029/ 2008RG000266.

Kim, D., J.-S. Kug, and A. H. Sobel, 2014: Propagating versus nonpropagating Madden-Julian oscillation events. J. Climate, 27, 111-125.

Kodama, C., A. T. Noda, and M. Satoh, 2012: An assessment of the cloud signals simulated by NICAM using ISCCP, CALIPSO, and CloudSat satellite simulators. J. Geophys. Res., 117, D12210, doi:10.1029/2011JD 017317.

Kodama, C., Y. Yamada, A. T. Noda, K. Kikuchi, Y. Kajikawa, T. Nasuno, T. Tomita, T. Yamaura, T. G. Takahashi, M. Hara, Y. Kawatani, M. Satoh, and M. Sugi, 2015: A 20-year climatology of a NICAM AMIP-type simulation. J. Meteor. Soc. Japan, 93, 393-424.

Kubota, H., K. Yoneyama, J. Hamada, P. Wu, A. Sudaryanto, and I. B. Wahyono, 2015: Role of maritime continent convection during the preconditioning stage of the Madden-Julian Oscillation observed in CINDY2011/ DYNAMO. J. Meteor. Soc. Japan, 93A, 101-114.

Li, T., C. Zhao, P.-C. Hsu, and T. Nasuno, 2015: MJO initiation processes over the tropical Indian Ocean during DYNAMO/CINDY2011. J. Climate, 28, 2121-2135.

Ling, J., P. Bauer, P. Bechtold, A. Beljaars, R. Forbes, F. Vitart, M. Ulate, and C. Zhang, 2014: Global versus local MJO forecast skill of the ECMWF model during DYNAMO. Mon. Wea. Rev., 142, 2228-2247.

Madden, R. A., and P. R. Julian, 1971: Detection of a 40-50 day oscillation in the zonal wind in the tropical Pacific. J. Atmos. Sci., 28, 702-708.

Madden, R. A., and P. R. Julian, 1972: Description of globalscale circulation cells in the Tropics with a 40-50 day period. J. Atmos. Sci., 29, 1109-1123.

Maloney, E. D., 2009: The moist static energy budget of a composite tropical intraseasonal oscillation in a climate model. J. Climate, 22, 711-729.

Maloney, E. D., and D. L. Hartmann, 1998: Frictional moisture convergence in a composite life cycle of the Madden-Julian oscillation. J. Climate, 11, 2387-2403.

Mellor, G. L., and T. Yamada, 1982: Development of a turbulent closure model for geophysical fluid problems. Rev. Geophys., 20, 851-875.

Miura, H., M. Satoh, T. Nasuno, A. T., Noda, and K. Oouchi, 2007: An Madden-Julian Oscillation event simulated using a global cloud-resolving model. Science, 318, 1763-1765.

Miura, H., T. Suematsu, and T. Nasuno, 2015: An ensemble hindcast of the Madden-Julian Oscillation during the CINDY2011/DYNAMO field campaign and influence of seasonal variation of sea surface temperature. $J$. Meteor. Soc. Japan, 93A, 115-137.

Miyakawa, T., M. Satoh, H. Miura, H. Tomita, H. Yashiro, A. T. Noda, Y. Yamada, C. Kodama, M. Kimoto, and K. Yoneyama, 2014: Madden-Julian Oscillation prediction skill of a new-generation global model demonstrated using a supercomputer. Nat. Commun., 5, 3769, doi:10.1038/ncomms4769.

Miyamoto, Y., Y. Kajikawa, R. Yoshida, T. Yamaura, H. Yashiro, and H. Tomita, 2013: Deep moist atmospheric convection in a subkilometer global simulation. 
Geophys. Res. Lett., 40, 4922-4926.

Moum, J. N., S. P. de Szoeke, W. D. Smyth, J. B. Edson, H. L. DeWitt, A. J. Moulin, E. J. Thompson, C. J. Zappa, S. A. Rutledge, R. H. Johnson, and C. W. Fairall, 2014: Air-sea interactions from westerly wind burst during the November 2011 MJO in the Indian Ocean. Bull. Amer. Meteor. Soc., 95, 1185-1199.

Nasuno, T., 2013: Forecast skill of Madden-Julian Oscillation events in a global nonhydrostatic model during the CINDY2011/DYNAMO observation period. SOLA, 9, 69-73.

Nasuno, T., and M. Satoh, 2011: Properties of precipitation and in-cloud vertical motion in a global nonhydrostatic aquaplanet experiment. J. Meteor. Soc. Japan, 89, 413-439.

Nasuno, T., T. Li, and K. Kikuchi, 2015: Moistening processes before the convective initiation of MaddenJulian oscillation events during the CINDY2011/ DYNAMO period. Mon. Wea. Rev., 143, 622-643.

Noda, A. T., K. Oouchi, M. Satoh, H. Tomita, S. Iga, and Y. Tsushima, 2010: Importance of the subgrid-scale turbulent moist process: Cloud distribution in global cloud-resolving simulations. Atmos. Res., 96, 208217.

Oouchi, K., H. Taniguchi, T. Nasuno, M. Satoh, H. Tomita, Y. Yamada, M. Ikeda, R. Shirooka, H. Yamada, and K. Yoneyama, 2012: A prototype quasi real-time intra-seasonal forecasting of tropical convection over the warm pool region: A new challenge of global cloud-system-resolving model for a field campaign. Cyclones: Formation, Triggers and Control. Oouchi, K., and H. Fudeyasu (eds.), Nova Science Publishers, Inc., 233-248.

Powell, S. W., and R. A. Houze, Jr., 2013: The cloud population and onset of the Madden-Julian Oscillation over the Indian Ocean during DYNAMO-AMIE. $J$. Geophys. Res., 118, 11979-11995.

Roh, W., and M. Satoh, 2014: Evaluation of precipitating hydrometeor parameterizations in a single-moment bulk microphysics scheme for deep convective systems over the tropical Central Pacific. J. Atmos. Sci., 71, 2654-2673.

Ruppert, Jr., J. H., and R. H. Johnson, 2015: Diurnally modulated cumulus moistening in the preonset stage of the Madden-Julian oscillation during DYNAMO. $J$. Atmos. Sci., 72, 1622-1647.

Sato, T., H. Miura, M. Satoh, Y. N. Takayabu, and Y. Wang, 2009: Diurnal cycle of precipitation in the tropics simulated in a global cloud-resolving model. J. Climate, 22, 4809-4826.

Satoh, M., T. Matsuno, H. Tomita, H. Miura, T. Nasuno, and S. Iga, 2008: Nonhydrostatic Icosahedral Atmospheric Model (NICAM) for global cloud-resolving simulations. J. Comput. Phys., 227, 3486-3514.

Satoh, M., T. Inoue, and H. Miura, 2010: Evaluations of cloud properties of global and local cloud system resolving models using CALIPSO and CloudSat simulators. J. Geophys. Res., 115, D00H14, doi:10.1029/ 2009JD012247.

Satoh, M., H. Tomita, H. Yashiro, H. Miura, C. Kodama, T. Seiki, A. T. Noda, Y. Yamada, D. Goto, M. Sawada, T. Miyoshi, Y. Niwa, M. Hara, Y. Ohno, S. Iga, T. Arakawa, T. Inoue, and H. Kubokawa, 2014: The Nonhydrostatic Icosahedral Atmospheric Model: Description and development. Prog. Earth Planet. Sci., 1, 18, doi:10.1186/s40645-014-0018-1.

Seiki, A., M. Katsumata, T. Horii, T. Hasegawa, K. J. Richards, K. Yoneyama, and R. Shirooka, 2013: Abrupt cooling associated with the oceanic Rossby wave and lateral advection during CINDY2011. J. Geophys. Res., 118, 5523-5535.

Sekiguchi, M., and T. Nakajima, 2008: A $k$-distributionbased radiation code and itscomputational optimization for an atmospheric general circulation model. $J$. Quant. Spectrosc. Radiat. Transfer, 109, 2779-2793.

Seo, H., A. C. Subramanian, A. J. Miller, and N. R. Cavanaugh, 2014: Coupled impacts of the diurnal cycle of sea surface temperature on the Madden-Julian oscillation. J. Climate, 27, 8422-8443.

Sobel, A. H., J. Nilsson, and L. M. Polvani, 2001: The weak temperature gradient approximation and balanced tropical moisture waves. J. Atmos. Sci., 58, 36503665 .

Sobel, A., S. Wang, and D. Kim, 2014: Moist static energy budget of the MJO during DYNAMO. J. Atmos. Sci., 71, 4276-4291.

Subramanian, A. C., and G. J. Zhang, 2014: Diagnosing MJO hindcast biases in NCAR CAM3 using nudging during the DYNAMO field campaign. J. Geophys. Res., 119, 7231-7253.

Sugiyama, M., 2009: Moisture mode in the tropics. Part I: Analysis based on the weak temperature gradient approximation. J. Atmos. Sci., 66, 1507-1523.

Tomita, H., 2008a: A stretched grid on a sphere by new grid transformation. J. Meteor. Soc. Japan, 86A, 107-119.

Tomita, H., 2008b: New micorphysics schemes with five and six categories by diagnostic generation of cloud ice. J. Meteor. Soc. Japan, 86A, 121-142.

Tomita, H., and M. Satoh, 2004: A new dynamical framework of nonhydrostatic global model using the icosahedral grid. Fluid Dyn. Res., 34, 357-400.

Tomita, H., H. Miura, S. Iga, T. Nasuno, and M. Satoh, 2005: A global cloud-resolving simulation: Preliminary results from an aqua planet experiment. Geophys. Res. Lett., 32, L08805, doi:10.1029/2005GL022459.

Tseng, K.-C., C.-H. Sui, and T. Li, 2015: Moistening processes for Madden-Julian oscillations during DYNAMO/CINDY. J. Climate, 28, 3041-3057.

Wang, S., A. H. Sobel, F. Zhang, Y. Q. Sun, Y. Yue, and L. Zhou, 2015: Regional simulation of the October and November MJO events observed during the CINDY/ DYNAMO field campaign at gray zone resolution. $J$. 
Climate, 28, 2097-2119.

Wheeler, M. C., and H. H. Hendon, 2004: An all-season real-time multivariate MJO index: Development of an index for monitoring and prediction. Mon. Wea. Rev., 132, 1917-1932.

$\mathrm{Xu}, \mathrm{W}$., and S. A. Rutledge, 2014: Convective characteristics of the Madden-Julian oscillation over the central Indian Ocean observed by shipborne radar during DYNAMO. J. Atmos. Sci., 71, 2859-2877.

Yanai, M., S. Esbensen, and J.-H. Chu, 1973: Determination of bulk properties of tropical cloud clusters from large-scale heat and moisture budgets. J. Atmos. Sci., 30, 611-627.

Yokoi, S., 2015: Multireanalysis comparison of variability in column water vapor and its analysis increment associated with Madden-Julian oscillation. J. Climate, 28, 793-808.

Yokoi, S., and A. H. Sobel, 2015: Intraseasonal variability and seasonal March of the moist static energy budget over the eastern Maritime Continent during CINDY2011/DYNAMO. J. Meteor. Soc. Japan, 93A, 81-100.

Yokoi, S., M. Katsumata, and K. Yoneyama, 2014: Variability in surface meteorology and air-sea fluxes due to cumulus convective systems observed during CINDY/ DYNAMO. J. Geophys. Res., 119, 2064-2078.

Yoneyama, K., C. Zhang, and C. N. Long, 2013: Tracking pulses of the Madden-Julian oscillation. Bull. Amer. Meteor. Soc., 94, 1871-1891.

Zhang, C., J. Gottschalck, E. D. Maloney, M. W. Moncrieff, F. Vitart, D. E. Waliser, B. Wang, and M. C. Wheeler, 2013: Cracking the MJO nut. Geophys. Res. Lett., 40, 1223-1230.

Zuluaga, M. D., and R. A. Houze, Jr., 2013: Evolution of the population of precipitating convective systems over the equatorial Indian Ocean in active phases of the Madden-Julian oscillation. J. Atmos. Sci., 70, 27132725 . 